\title{
Price Setting during Low and High Inflation: Evidence from Mexico
}

\author{
Etienne Gagnon* \\ Northwestern University
}

January 2006

\begin{abstract}
This paper provides new insight into the relationship between inflation and consumer price setting by examining a large data set of Mexican consumer prices covering episodes of both low and high inflation, as well as the transition between the two. The overall portrait is one in which the economy shares several characteristics of time dependent models when the annual inflation rate is low (below 10-15\%), while displaying strong state dependence when inflation is high (above 10-15\%). At low inflation levels, the aggregate frequency of price changes responds little to movements in inflation because movements in the frequency of price decreases partly offset movements in the frequency of price increases. When the annual inflation rate is above 10-15 percent, however, there are no longer enough price decreases to counterbalance price increases, making the frequency of price changes much more responsive to inflation. In this case, a 1-percent increase in the annual inflation rate is associated with a $0.40-0.45$-percentage-points increase in the monthly frequency of price changes for consumer goods.
\end{abstract}

JEL classification: E31, D40, C23.

Keywords: Price setting, consumer prices, frequency of price changes, time-dependent pricing, state-dependent pricing.

${ }^{*}$ I would like to thank my advisors, Lawrence J. Christiano, Alexander Monge-Naranjo, Sergio Rebelo, and especially Martin Eichenbaum, for their continuous guidance and support. I also am grateful to Martin Bodenstein, Jeff Campbell, Reinout DeBock, Rodrigo García Verdú, Jon Huntley, Eugene Orlov, Nicolas Vincent and seminar participants at the Economic Research Division of Banco de México for their insightful comments and suggestions. Chris Ahlin, Allan Collard-Wexler, Martha Carillo and José Antonio Murillo Garza provided valuable help with the data. Financial support for this research was provided in part by the Center for International Economics and Development (CIED), Northwestern University Graduate Research Grant and the Fonds québécois pour les chercheurs et l'aide à la recherche (FCAR). All errors and omissions are mine. Comments are welcome; please direct them to e-gagnon@northwestern.edu. 


\section{Introduction}

This paper assesses the empirical plausibility of competing models of price rigidities using a new data set of store-level prices that I assembled. This data set contains more than six million individual price quotes and is representative of more than two-thirds of Mexican consumers' expenditures. The data starts in January 1994 and ends in December 2004. Over that 11-year period, CPI inflation rose from $6.8 \%$ in 1994 to a high of $41.8 \%$ in 1995 before falling to a low of $3.9 \%$ in 2001 . Given these considerable fluctuations, this data set has the potential to shed light on competing models of nominal price rigidities, as these models' predictions diverge most when inflation is volatile.

Many macroeconomic models assume that price rigidities exist. There is, however, no consensus on how to model these rigidities. In time-dependent models, the set of firms optimizing their prices is fixed exogenously within the period. ${ }^{1}$ In state-dependent models, on the other hand, the timing of price changes is an endogenous decision. In these models, price stickiness results from frictions like menu costs, imperfect or costly information and shifts in demand that accompany price changes. ${ }^{2}$ Recently, several authors have argued that variants of time-dependent models can deliver empirically plausible predictions despite their simplicity. ${ }^{3}$ Even advocates of time-dependent models would agree, however, that the performance of these models should decline as inflation becomes large or volatile. The inflation level at which time-dependent models break down remains an open question, as does the more general question of what price-setting models are empirically plausible at both low and high inflation levels.

My data set captures considerably more variation in inflation than do other studies of consumer prices with comparable product coverage. ${ }^{4}$ As Figure 1 indicates, inflation is low and stable in the United States and Euro area relative to Mexico over the periods these studies cover. In the case of high-inflation economies, the evidence is limited mainly to food products in Israel (Lach and Tsiddon, 1992; Baharad and Eden 2004) and Poland (Konieczny and Skrzypacz, 2005) and supermarket products in Argentina (Burstein, Eichenbaum and Rebelo, 2005). This paper differs from these studies because my data set is representative of most goods and services in the CPI with the exception of housing, and I provide evidence for both

\footnotetext{
${ }^{1}$ Time-dependent models include Taylor's (1980) staggered pricing model, in which firms optimize every $n$ periods, and the Calvo (1983) model, in which firms face a constant probability $1 / n$ of optimizing their prices. Recent implementations of time-dependent rules can be found, for example, in Chari, Kehoe and McGrattan (2002); Christiano, Eichenbaum and Evans (2005); Gali and Gertler (1999); and Smets and Wouters (2003).

${ }^{2}$ For a modern treatment of menu-cost models, see, for example, Dotsey, King and Wolman (1999); Golosov and Lucas (2003); Burstein (2005); and Gertler and Leahy (2005). Recent development in models of information frictions includes Mankiw and Reis (2002); Sims (2003); and Maćkowiak and Wiederholt (2005). Other statedependent approaches include fair-pricing models (Rotemberg 2002, 2004) and uncertain and sequential trading (e.g., Eden 1994; Lucas and Woodford, 1993).

${ }^{3}$ See Klenow and Kryvtsov (2005), Burstein (2005) and Eichenbaum and Fisher (2005).

${ }^{4}$ For studies on the United States, see Bils and Klenow (2004) and Klenow and Kryvtsov (2005). Dhyne et al. (2005) review the main findings for the Euro area.
} 
high and low levels of inflation.

I find sharp differences in the price-setting behaviors of low- and high-inflation economies: Whereas low-inflation economies exhibit several features of time-dependent pricing models, high-inflation economies show strong state dependence. More specifically, when inflation is low (below 10-15\%), the frequency of price changes is only mildly correlated with inflation, especially when I restrict the sample to nonregulated goods, in which case I find no correlation. On the other hand, the average magnitude of price changes in such low-inflation environments displays a tight and linear relationship with inflation. As a result, movements in the frequency of price changes account for little of the inflation variance: about $15 \%$ for nonregulated products and $5 \%$ for nonregulated goods, figures that fall in line with Klenow and Kryvtsov's (2005) for the United States (5\%).

In contrast, when inflation is high (above 10-15\%), both the frequency and average magnitude of price changes are strongly correlated with inflation. In this case, a 1-percent increase in the annual inflation rate is associated with a 0.40-0.45-percentage-point increase in the monthly frequency of price changes for nonregulated consumer goods. Movements in the frequency price changes therefore comprise an important component of inflation variance. This central role of the frequency of price changes in inflation dynamics is best revealed by a rise of the value added tax from 10 to $15 \%$ in April 1995: The adjustment of prices occurs almost entirely through an increased frequency of price changes — not an increased magnitude and is completed within a month of the tax change.

Price decreases are key to the dramatically different behaviors of low- and high-inflation economies. When I decompose the frequency of price changes as the sum of the frequencies of price increases and decreases, I find that the frequency of price decreases diminishes rapidly as inflation rises from 0 to $10-15 \%$. This effect partly offsets a simultaneous rise in the frequency of price increases, thereby dampening movements in the overall frequency of price changes. Moreover, the decline in price decreases relative to price increases leads to a rise in the average magnitude of price changes. This change in the composition of price changes largely explains the strong correlation between inflation and the average magnitude of price changes in my data when inflation is low. Once inflation moves beyond 10-15\%, however, there are no longer enough price decreases to offset price increases, so the frequency of price changes becomes highly correlated with inflation.

The important role of price decreases for inflation dynamics in Mexico is likely to be found in the United States. At similar levels of inflation, price decreases account for $42 \%$ of price changes in Mexico compared to $45 \%$ in the United States (Klenow and Kryvtsov 2005). For most groups of products, however, price changes are more frequent in the United States. I conjecture that the greater number of price decreases in the United States relative to Mexico likely will have similar offsetting effects on the frequency of price changes.

In order to characterize individual firms' pricing decisions in terms of time and state 
dependence, I estimate a fixed-effects logit model on the probability of observing a price change. ${ }^{5}$ I then use my estimates to construct the hazard function of price changes. In the case of unprocessed food items, I show that the offsetting effect described earlier is strong enough to keep the hazard roughly constant as inflation rises from zero to 30 percent per year for durations of 12 months or less. For processed food and nonenergy industrial goods, I find evidence that the slope of the hazard is increasing with the time elapsed since the last price change, a prediction of several state-dependent models.

My findings shed light on what types of pricing models deliver realistic predictions at various levels of inflation. Overall, my results suggest that pricing models should endogenize the timing of price changes if they wish to make realistic predictions at both low and high inflation levels. Above a 10-15\% inflation rate, the predictions of time-dependent models are clearly inconsistent with the strong state-dependence with respect to inflation found in my data. When inflation falls below 10-15\%, the muted response of the frequency of price changes in the good sectors is consistent, at least on the surface, with time-dependent models like Calvo. Time-dependent models typically abstract, however, from the fact that both the frequencies of price increases and decreases comove with inflation. It remains to be explored how abstracting from price decreases affects the predictions of these models. The introduction of price decreases may be even more important in state-dependent models, as it could help reduce the counterfactually high correlation between the frequency of price changes and inflation in models such as Dotsey, King and Wolman (1999).

The paper is organized as follows. In the next section, I provide a brief overview of the Mexican macroeconomic context over the sample period. In Section 3, I describe the assemblage of my data set and discuss features of the data that are important for interpreting my results. Then, Section 4 defines the statistics computed in this paper. In section 5, I explain how the average frequency and magnitude of individual price changes differ across low- and high-inflation episodes, and I investigate the inflation pass-through resulting from an April 1995 hike in the value added tax. In Section 6, I compare consumer price stickiness in the Mexican economy to that in the United States and the Euro area. In Section 7, I estimate a fixed-effect logit on the probability of observing a nominal price adjustment to characterize it in terms of time- and state-dependent elements. Section 8 discusses the implications of my results for choosing a pricing model. Finally, the last section provides concluding remarks.

\footnotetext{
${ }^{5}$ Cecchetti (1986) first used this approach to study newsstand magazine prices. The set of regressors is extended along the lines of Aucremanne and Dhyne (2005) to account for price decreases and time dependence in my sample.
} 


\section{The Macroeconomic Context}

The sample period was marked by a severe economic downturn in the wake of the December 1994 peso devaluation. To most observers of the Mexican economy, however, 1994 opened rather positively. ${ }^{6}$ Inflation had been stabilized successfully below 10 percent, a major achievement in light of the three-digit rates of the late $1980 \mathrm{s.}^{7}$ The real interest rate also had decreased. The excess return on the three-month, dollar-denominated Tesobonos was only two percentage points above the American T-Bill. The budget deficit, seen by many as the culprit of previous economic crises, had been eliminated in 1992. Moreover, the North American Free Trade Agreement had taken effect on January 1, 1994. This treaty was part of a broad set of Mexican government initiatives to deregulate the country's economy and open it to foreign trade and capital. Foreign capital entered abundantly with a net inflow over $8 \%$ of GDP in 1993. However, growth in real GDP per capita remained modest, averaging $2.5 \%$ from 1991 to 1993. Many observers saw this situation as part of a restructuring process that soon would bring strong growth to the country.

The devaluation brought a radical change of mood. On December 22, 1994, the exchange rate collapsed and lost more than $40 \%$ of its value vis-à-vis the U.S. dollar in the week that followed. ${ }^{8}$ As depicted in Figure 2, interest rates were pushed upward substantially as Banxico tightened the supply of money to prevent further erosion of the peso and a capital flight. The devaluation left a major stagflation in its wake. Inflation took off almost immediately, increasing from $6.5 \%$ in November 1994, to $44.3 \%$ in January 1995 before peaking at $92.0 \%$ in April 1995. Real output per capita contracted by $9.5 \%$ in 1995, while private consumption per capita fell by a solid $13.2 \%$. Mexicans would have to wait until 1998 for real GDP per capita to surpass its 1994 level and until 1999 for inflation to settle below $10 \%$.

The decline in aggregate income, coupled with a rise in fiscal evasion, brought a sharp decline in government revenues. ${ }^{9}$ To prevent further revenue erosion, the government raised the general rate of the value added tax rate (VAT) from 10 to 15 percent on April 1, 1995. This change affected all Mexican regions, with the notable exceptions of Baja California and a corridor along the country's southern and northern borders where the rate remained at $10 \%$.

\footnotetext{
${ }^{6}$ See Edwards (1997) for a review of observers' opinions in 1994.

${ }^{7}$ Unless otherwise indicated, all percentage figures are in logartihmic differences. The inflation rate is the annualized change in the CPI over the previous month.

${ }^{8}$ Mexico pegged its exchange rate to the dollar in May 1992. In February 1994, the country switched to pre-announced crawling bands around the U.S. dollar.

${ }^{9}$ See OECD Economic Surveys: Mexico 1999 for a detailed description of the taxation system.
} 


\section{Mexican Micro Data on Consumer Prices}

\subsection{Description of Sources}

The data comprise price quotes collected by Banco de México (Banxico) for computing the Mexican CPI. Most price quotes correspond to narrowly defined items sold in specific outlets (e.g., corn flour, brand Maseca, bag of 1 kg, sold in outlet 1100 in Mexico City). A limited number of quotes are city-wide indexes, or the average price of a small sample of narrowly defined items belonging to the same category and outlet. Since January 1994, the official gazette of the Mexican government, the Diario Oficial de la Federación, has published price quotes. This publication releases each quote with a key linking the item to a specific outlet, city and good category; these keys allow me to track individual prices over time. ${ }^{10}$ In this paper, I refer to an item's complete price history as its price trajectory. A price trajectory comprises one or several successive price spells, episodes when the price remained constant.

The data set contains 6.5 million price quotes from January 1994 to December 2004. Banxico makes individual prices available up to six months after their publication, but it does not keep a historical data set of individual prices. The data set was assembled by merging the information released in the Diario. The data for the months of January 1994 to February 1995 could not be extracted electronically, so they were typed from original hard paper copies of the Diario using double-entry keying, a process ensuring a character-wise accuracy in excess of $99.998 \% .^{11}$ About 430,000 price quotes were added to the database in this way.

Precise item descriptions were published in March 1995 and August 2002. The Diario also includes lists of items that are periodically added, dropped or substituted from the CPI basket. Unlike additions, substitutions are not planned events. They occur when the characteristics of an item (weight, size, model, presentation, etc.) change, when an outlet stops carrying an item or, in rarer cases, when an outlet goes out of business.

The weights used in the CPI are derived from the Survey of Households' Income and Expenditures (ENIGH). The CPI categories are representative of all ENIGH categories accounting for at least 0.02 percent of households' expenditures. This ensures a coverage well above $95 \%$ of Mexican households' expenditures.

\subsection{Sample coverage}

In January 1994, the CPI contained 30,692 price quotes spread over 302 categories. By December 2004, it had expanded to more than 60,000 price quotes distributed over 315 categories. Two major revisions of the basket occurred over that period. The first occurred in March 1995, when the number of cities covered in the CPI grew from 35 to 46. At the same time, 29

\footnotetext{
${ }^{10}$ Items from the same outlet are attributed store keys independently to ensure confidentiality.

${ }^{11}$ I thank Chris Ahlin for lending me original copies of the Diario.
} 
new good categories were introduced into the basket, and 18 were abandoned. This revision had been planned long before the peso's devaluation. Secondly, in July 2002, Banxico updated the basket again to reflect the structure of Mexican households' consumption in 2000. In the process, 60 product categories merged into 27, another 36 were introduced into the basket and one was dropped. I cannot link items before and after the 2002 basket revision because of a change to the item keys.

To ensure the greatest comparability across time, I compute my core results for a sample covering January 1994 - June 2002 using the expenditure weights implemented in March 1995. ${ }^{12}$ Unless otherwise indicated, the sample is restricted to the 274 product categories comprising individual prices that were unaffected by the 1995 basket revision. ${ }^{13}$ This restricted sample covers $69.8 \%$ of CPI expenditures. The largest three excluded product categories are homeowners' imputed rents, gasoline and rents, whose weight in the CPI are respectively $11.6 \%, 3.2 \%$ and $2.4 \%$. This more homogenous sample contains 4.5 million price quotes from nearly 62,000 price trajectories. Summary statistics of the data used in this paper are provided in Table 1.

\subsection{Other Aspects of the Data}

I now address features of the data that are important to consider when interpreting of the results. The most significant issue is price averaging. Banxico collects prices twice monthly for all items but food; food price collection occurs four times per month. ${ }^{14}$ The collected prices are then averaged to produce the monthly figures reported in the Diario. Unfortunately, observing the monthly average rather than the actual price of an item complicates the inference about price changes. For example, an average price of $\$ 2$ for an item is consistent with an actual price of $\$ 2$ throughout the month. It also is consistent with an actual price of $\$ 1.50$ in the first half of the month and $\$ 2.50$ in the second, or any combination of positive prices with $\$ 2$ as their average. Moreover, changes to an average price series are typically more frequent and of smaller magnitude than changes to an actual price series. For example, a price hike from $\$ 1.50$ to $\$ 2.50$ in the middle of the month results in an average price of $\$ 2$, which is $\$ 0.50$ short of the new actual price. Thus, if the actual price remains constant over the next month, another change to the average price series will be recorded.

To make my results as comparable as possible to other studies, which do not use averaged

\footnotetext{
${ }^{12}$ These weights are derived from the 1989 ENIGH survey. They were updated using relative prices to reflect consumer expenditures in 1993.

${ }^{13}$ Ten product categories common to both periods were dropped in the analysis because they contained indexes rather than individual observations. To check the representativeness of this restricted sample, I computed the main statistics in Section 5 using all product categories with individual observations after the 1995 revision. Differences in the results were negligible.

${ }^{14}$ In the United States, the BLS collects prices monthly for food consumed at home, energy, and a few additional items with volatile prices. Other prices are collected monthly for the three largest metropolitain areas (New York, Los Angeles, and Chicago) and every other month for the remaining areas.
} 
price quotes, I have constructed alternative price trajectories that filter the effect of averaging observations whenever possible. These new series correspond to the end-of-month series of actual prices, which are both consistent with the published averages and minimizes the number of price changes. In addition to being closer to the unobserved series of actual prices, the filtered series provide a lower bound on how frequently prices change. Appendix A discusses details of the filtering procedure.

Another issue in the data is that price collectors do not always directly observe prices. Indeed, sometimes an item is out of stock, out of season or, in rarer cases, the outlet is closed when the CPI agent visits. In such situations, the price from the previous period is carried forward. Although I cannot identify prices that were imputed in my sample, I do find clear indications that the number of imputations was larger at the beginning of the sample. Item substitutions represented less than $0.1 \%$ of all price quotes in 1994, a proportion that rose to $1.2 \%$ in 2001 and $3.0 \%$ in 2004; this trend likely will create a downward bias in the estimated frequency of price changes at the beginning of the sample. ${ }^{15}$

Furthermore, prices are inclusive of sales as long as they are conditional on the purchase of a single item. For example, in a 3 -for-2 promotion, the regular price would be reported. In such cases, the unobserved effective price is lower than the observed reported price. There is no variable in the data set signaling that an item is on sale or that a promotion is ongoing. To assess the prevalence of sales in the sample, I define sales as a price spell that lasts three months or less, begins with a price decrease and is ended by a price increase of the same magnitude. When goods are weighted by expenditure shares, sales amount to $5 \%$ of price changes over the sample period and $9 \%$ over the year prior before the 2002 basket revision. These figures are lower than the $20 \%$ reported by Klenow and Kryvtsov for the United States (cited by Bils and Klenow 2004). This difference likely reflects a greater prevalence of sales and promotions in the United States than Mexico as well as methodological differences. ${ }^{16}$ All the results in my paper are inclusive of unconditional sales.

In interpreting the data, one must also consider that most price quotes for the product categories of textiles, clothing, shoes and their related accessories are an average of a small sample of item prices; all items within a sample pertain to the same outlet whenever possible. Using the descriptions published in the Diario, I identified the exact number of items and brands within each store sample. A store sample typically contains two to four items (e.g., two cotton-based pants for men, brands Lee and Cimarron), with a mode of three for the number of both items and brands. Price changes generally are more frequent and of smaller

\footnotetext{
${ }^{15}$ A more systematic treatment of substitutions was implemented in 2001. Prices can now be carried forward for at most a month and a half before a substitution is sought. If the scarcity is generalized, this allowance can be extended up to three months. Systematic rotation of items was introduced in July 2002 to keep the CPI basket up to date.

${ }^{16}$ The BLS reports prices net of sales and promotions whenever possible. For example, a 3 -for- 2 promotion would result in a temporary $33 \%$ price decrease.
} 
magnitude for a sample than for its individual components, but the severity of this divergence depends on the price synchronization within the sample. For example, if an outlet runs a $30 \%$ sale on all jeans, then the average price of a sample of three pairs of jeans also decreases by $30 \%$. I discard all store samples whenever a product category contains a large proportion of individual observations. For 34 categories encompassing all clothing and shoes categories except school uniforms, I retain only samples comprising three items and discard all other observations. I then treat those observations like other individual observations. Appendix B explores the extent of the bias this procedure introduces.

A final issue is that item substitutions often accompany changes in product characteristics, thereby raising raising the question of whether substitutions should be treated as price changes. The Inflation Perisitence Network's approach is to assume that all substitutions not previously planned by the CPI agency involve a price change. In this paper, I instead exclude all substitutions from the computation of price changes because their treatment varies over the sample period. The main conclusions are not affected by this decision.

\subsection{Example of Individual Price Trajectory}

Figure 3 illustrates the raw data and shows how the effect of averaging several price observations over the month is filtered. It displays two years of monthly average prices for a copy of the book "The Universal History of Literature" sold in a Mexico City outlet. This series was computed by Banxico by averaging the two prices its CPI agent collected each month. From January 1994 to December 1995, there were six changes to the series. The first happened in August 1994 when the average price increased from $\$ 23$ to $\$ 25$. Because the average price remained at $\$ 25$ in September, I conclude that the two prices collected in August also equaled $\$ 25$. The next two changes occurred in January and February 1995. The published price for January, $\$ 28.5$, is the exact average of the published prices for December and February ( $\$ 25$ and $\$ 32$, respectively). This figure is consistent with the occurrence of a single change in the actual price from $\$ 25$ to $\$ 32$ during the second half of January. The last three price changes occurred in May, June and July of 1995; the published price increased from $\$ 32$ to $\$ 36.5$, then to $\$ 47$ and finally to $\$ 53$. This series is consistent with a change in the actual price from $\$ 32$ to $\$ 41$ after the first price collection in May and then $\$ 41$ to $\$ 53$ after the first price collection in June. The filtered series, which contains only the last observation of each month, is displayed at the bottom of Figure 2. It contains only four price changes, and their magnitude is greater on average than those in the published average price series. 


\section{Inflation Accounting Principles}

Whenever a price is reported for two consecutive months, an indicator that a price change has occurred is created:

$$
I_{i t}= \begin{cases}1 & \text { if } p_{i t} \neq p_{i t-1} \\ 0 & \text { if } p_{i t}=p_{i t-1}\end{cases}
$$

where $p_{i t}$ is the price of item $i$ (in logs) during month $t$. Inflation is defined as

$$
\pi_{t} \triangleq \sum_{i \in \Upsilon_{t}} \omega_{i t} \pi_{i t}
$$

where $\pi_{i t}=p_{i t}-p_{i t-1}, \omega_{i t}$ is the weight of item $i$, and $\Upsilon_{t}$ is the set of all items for which $I_{i t}$ is defined. For $\omega_{i t}$, I use the weight of the CPI category to which item $i$ belongs, divided by the number of items in that category for which I can compute a price change at $t$. Inflation also can be expressed as

$$
\pi_{t} \triangleq \underbrace{\left(\sum_{i \in \Upsilon_{t}} \omega_{i t} I_{i t}\right)}_{f r_{t}} \underbrace{\left(\frac{\sum_{i \in \Upsilon_{t}} \omega_{i t} I_{i t} \Delta p_{i t}}{\sum_{i \in \Upsilon_{t}} \omega_{i t} I_{i t}}\right)}_{d p_{t}}
$$

The term $f r_{t}$, henceforth referred to as the frequency of price changes, is the total CPI weight of items whose price changes at $t$. The term $d p_{t}$ is the average magnitude of those price changes. In the popular Calvo and Taylor models with uniform staggering of price changes, $d p_{t}$ is the only possible source of variation in $\pi_{t}$.

It is convenient to decompose inflation further into a weighted sum of price increases and decreases:

$$
\pi_{t} \triangleq \underbrace{\left(\sum_{i \in \Upsilon_{t}} \omega_{i t} I_{i t}^{+}\right)}_{f r_{t}^{+}} \underbrace{\left(\frac{\sum_{i \in \Upsilon_{t}} \omega_{i t} I_{i t}^{+} \Delta p_{i t}}{\sum_{i \in \Upsilon_{t}} \omega_{i t} I_{i t}^{+}}\right)}_{d p_{t}^{+}}+\underbrace{\left(\sum_{i \in \Upsilon_{t}} \omega_{i t} I_{i t}^{-}\right)}_{f r_{t}^{-}} \underbrace{\left(\frac{\sum_{i \in \Upsilon_{t}} \omega_{i t} I_{i t}^{-} \Delta p_{i t}}{\sum_{i \in \Upsilon_{t}} \omega_{i t} I_{i t}^{-}}\right)}_{d p_{t}^{-}}
$$

This decomposition carries information about the relationship between the distribution of price changes and inflation. In the next section, the frequency of price increases and decreases, $f r_{t}^{+}$and $f r_{t}^{-}$, will play a central role in the dynamics of inflation.

The statistic $f r_{t}$ yields information about the economy's degree of price stickiness; all else equal, the greater $f r_{t}$ is, the more flexible prices are. A closely related measure of price stickiness is the duration of price spells. Although price spells' length can be measured directly in the data, the literature generally has preferred duration measures derived from the frequency of price changes. Assuming price changes occur at a constant rate over the month, the average duration is given by $d u r_{t}=-1 / \ln \left(1-f r_{t}\right)$. Aggregate measures of average or 
median durations are obtained by computing $f r_{t}$ and $d u r_{t}$ at the category level and then aggregating them using the CPI product category weights. ${ }^{17}$

\section{Main Results}

This section presents the main results regarding the frequency and magnitude of price changes and emphasizes their relationships to inflation. I leave aside all price-regulated goods and services and focus on the behavior of prices that are free to adjust. I also temporarily exclude nonregulated services because several of them, most notably Education Services, have strong seasonal components.

\subsection{Frequency}

Movements in the frequency of price changes and inflation were very large over the sample period. In April 1995, the rate of inflation for nonregulated goods peaked at $85.9 \%$ (7.2\% in monthly terms). This rate is much greater than the 7.2 percent average in 1994 and the 1.8 percent average in the last year of the sample. The frequency of price changes also peaked in April 1995, when the price of $64.7 \%$ of nonregulated goods, measured in CPI weight, changed over that month. This number is more than twice the average level of $25.3 \%$ in 1994 and $31.5 \%$ in the last year of the sample.

Positive comovement between $f r_{t}$ and $\pi_{t}$ is clearly visible in Figure 4 . The correlation coefficient between the two linearly detrended series equals 0.93 for the whole period. This correlation is largely driven by the high inflation episode, however; it falls to -0.01 if I consider only the last three years of the sample. After mid-1996, it is difficult to spot any downward trend in the frequency of price changes even though inflation trends down. The reason behind this loose relationship is apparent in the middle of Figure 4, where I break down $f r_{t}$ into $f r_{t}^{+}$and $f r_{t}^{-}$. As inflation declined, so did the frequency of price increases. At the same time, however, price decreases became more frequent, thereby dampening movements in the frequency of price changes. A look at the correlation between $f r_{t}^{+}, f r_{t}^{-}$and $\pi_{t}$ provides further evidence of this dampening effect. In the last three years of the sample, the correlation is 0.57 between $f r_{t}^{+}$and $\pi_{t}$ and -0.70 between $f r_{t}^{-}$and $\pi_{t}$. (All series are linearly detrended.) The net result is an absence of correlation between $f r_{t}$ and $\pi_{t}$ over that period.

The offsetting effect of price decreases operates mainly at low levels of inflation. Indeed, when inflation reaches above 10 to $15 \%$ in my sample, there are few price decreases left to offset movements in the frequency of price increases. At the peak of inflation, for example, only $8 \%$ of price changes were price decreases. In contrast, $45 \%$ of price changes were negative in the last year of the sample (42\% if I include nonregulated services), a figure echoing those

\footnotetext{
${ }^{17}$ The above average duration measure is biased downward because of Jensen's inequality. See Baharad and Eden (2003) and Dhyne et al. (2005) for a discussion of this bias.
} 
on the United States and the Euro area. This disappearance of price decreases creates the observed nonlinearity in the relationship of $f r_{t}$ to $\pi_{t}$.

Figure 5 shows evidence of the offsetting effect from a different angle by presenting scatterplots of $f r_{t}, f r_{t}^{+}$and $f r_{t}^{-}$against the inflation rate. The sample is divided into low- and high-inflation subsamples. The low-inflation subsample features a rapid fall in the frequency of price decreases as inflation takes off, thereby generating the offsetting effect. In comparison, in the high-inflation subsample, the frequency of price decreases is closer to its lower bound and responds less directly to movements in inflation. This change in behavior, seen as a "kink" in the relation, occurs for an inflation rate of $10-15 \%{ }^{18}$ The plots also show the predicted values from simple linear regressions on each subsample, using $12.5 \%$ as the cutoff inflation. The regression results are presented in Table 2.

When inflation is high, there is a clear positive relation between $f r_{t}$ and $\pi_{t}$ : each percentagepoint increase in the annual inflation rate is associated with a $0.42(0.03)$ percentage-point increase in the frequency of price changes of nonregulated goods. ${ }^{19}$ In stark contrast, in the low-inflation subsample, the frequency of price changes shows no statistical relation to inflation in the low inflation subsample; the best point estimate for the slope of the regression line is actually negative at $-0.02(0.07)$. The reason behind this very different behavior of $f r_{t}$ over the low- and high-inflation subsamples can be understood by taking a second look at $f r_{t}^{+}$and $f r_{t}^{-}$. When inflation is low, a one percentage-point change in the inflation rate has a similar effect in magnitude on $f r_{t}^{+}$and $f r_{t}^{-}, 0.31(0.07)$ versus $-0.33(0.04)$, but this effect takes opposite signs. The net effect renders unresponsive $f r_{t}$ to movements in inflation. As inflation moves toward high values, however, the rate at which $f r_{t}^{-}$falls decreases as it approaches its lower bound of 0 . The frequency of price increases still has room to respond, though, resulting in the significant, positive statistical relationship that surfaces between $f r_{t}$ and $\pi_{t}$.

The offsetting effect of price decreases when inflation is low is robust to choosing any cutoff for the low- and high-inflation subsamples within the $10-15 \%$ range. Furthermore, the results are similar if I include nonregulated services, if I drop observations before the 1995 sample revision or around the inflation peak, and if I exclude all small-store samples.

\subsection{Magnitude of Price Changes}

Contrary to the frequency of price changes, the average magnitude of price changes moves strongly with inflation, regardless of whether inflation is low or high. The series $d p_{t}$ and

\footnotetext{
${ }^{18} \mathrm{~A}$ more formal way of choosing this cutoff is to regress the frequency of price decreases on inflation, allowing for a break in the relation. The hypothesis that the coefficients are equal for the two subsamples is rejected at the $1 \%$ for all points over that interval. Formal tests for choosing the break's location are sensitive to dropping all observations before April 1995.

${ }^{19}$ The number in parentheses is the standard error.
} 
$\pi_{t}$, displayed in Figure 6, follow similar patterns over the sample period. ${ }^{20}$ They register sharp increases during the Tequila crisis, followed by a protracted decline and ultimately a stabilization. The correlation between the two linearly detrended series is 0.939 over the full sample period. The high inflation episode does not drive this strong correlation, as was the case with the frequency of price changes; indeed, the correlation actually rises to a solid 0.998 over the last three years of the sample. As the scatterplot of $d p_{t}$ against $\pi_{t}$ (Figure 7) indicates, $d p_{t}$ and $\pi_{t}$ have a tight, almost linear relation when inflation is below $1 \%$ per month, or roughly 10-15 percent per year. When inflation is greater than $1 \%$ per month, the relation is still strongly positive, albeit noisier and slightly concave.

These results should come as no surprise given the findings described earlier regarding the frequency of price changes and inflation. By definition, $\pi_{t}=f r_{t} \cdot d p_{t}$. When inflation is low, $f r_{t}$ moves little with inflation, implying that $d p_{t}$ moves strongly and almost linearly with $\pi_{t}$. In contrast, when inflation is greater than $10-15 \%$ per year, $f r_{t}$ moves strongly and positively with $\pi_{t}$. This second source of variation in $\pi_{t}$ introduces some curvature as well as some noise in the relationship between $\pi_{t}$ and $d p_{t}$.

To better understand what drives $d p_{t}$, it is convenient to express it as

$$
d p_{t}=s_{t} \cdot\left|d p_{t}^{+}\right|-\left(1-s_{t}\right) \cdot\left|d p_{t}^{-}\right|
$$

where $s_{t}=f r_{t}^{+} /\left(f r_{t}^{+}+f r_{t}^{-}\right)$is the fraction of price increases among price changes. Thus, variations in the absolute magnitude of price increases and decreases, as well as their relative occurrence (the composition effect), affects the average magnitude of price changes. It is clear from Figure 6 that $\left|d p_{t}^{+}\right|$and $\left|d p_{t}^{-}\right|$are less correlated with inflation than $d p_{t}$. The point estimates for the correlation over the full sample are 0.685 and 0.166 , respectively. Moreover, $\left|d p_{t}^{+}\right|$and $\left|d p_{t}^{-}\right|$display much less variation over the sample period than their weighted sum. ${ }^{21}$ Except for a short period around the peak of inflation, the two series show relatively small oscillations around their sample mean: $9.2 \%$ for price increases and $10.5 \%$ for price decreases. This pattern leaves a potentially large role for movements in $s_{t}$ to affect average price change. The relation between inflation and $\left|d p_{t}^{+}\right|$or $\left|d p_{t}^{-}\right|$also is much noisier than the relation between inflation and $d p_{t}$. The bottom of Table 2 presents results from linear regressions of the magnitude of price changes on inflation. There is no significant statistical relationship between $\left|d p_{t}^{+}\right|$and $\pi_{t}$ in the low-inflation sample nor between $\left|d p_{t}^{-}\right|$and $\pi_{t}$ in the high- inflation subsample.

To assess the importance of this composition effect, I compute two counterfactual series in Figure 6. I obtain the first by holding $s_{t}$ at its sample mean to show how movements in $\left|d p_{t}^{+}\right|$ and $\left|d p_{t}^{-}\right|$alone affect $d p_{t}$. In the second series, $\left|d p_{t}^{+}\right|$and $\left|d p_{t}^{-}\right|$are held at their sample

\footnotetext{
${ }^{20}$ The inflation series is the nonannualized monthly inflation rate to facilitate visual comparisons.

${ }^{21}$ The few large spikes in $d p_{t}^{-}$, all occuring at the beginning of the year, stem from seasonal variations in the price of a few fresh food items.
} 
mean so the relative occurrence of price increases and decreases is the only source of variation in $d p_{t}$. The main finding indicates that the composition effect drives $d p_{t}$ when inflation is below 10-15\%, whereas movements in both the composition and absolute magnitude of price changes are important when inflation is high. Had $s_{t}$ been constant, $d p_{t}$ would have sloped up counterfactually in the last three years of the sample because of a mild upward trend in $d p_{t}^{+}$ after 1999. In contrast, the series allowing only for the composition effect predicts remarkably well the level of $d p_{t}$ over that period. When inflation nears its peak, the composition effect alone is insufficient to match the level of $d p_{t}$, but it is a better predictor than merely allowing for changes in the absolute magnitude.

\subsection{Distribution of Price Changes}

There is much heterogeneity in the size of price changes at all levels of inflation. The distribution of price changes is very spread out; both small and large price changes arise (see Figure 8). ${ }^{22}$ When inflation is low, many large and small price decreases occur. Furthermore, the entire distribution shifts to the right as inflation increases. On the other hand, price decreases, which are almost as frequent as price increases at low inflation, become less prevalent as inflation rises. This behavior leads to the weak response of the frequency and the strong response of the magnitude of price changes discussed earlier.

When inflation is high, price increases between 0 and $20 \%$ compose the bulk of price changes. The increased density of this region comes from two sources. First, prices that change often - food products in particular - see their distribution moving up. Second, several prices that would have remained fixed otherwise are updated by positive amounts. Recall that the price of $59.1 \%$ of all nonregulated items changed in April 1995 compared with only $25.6 \%$ in the last year of the sample.

The distributions are not symmetric, even when inflation is at its lowest. Indeed, small decreases are less frequent than small increases. Furthermore, price increases are more spread out than price decreases when inflation is high, but the opposite is true when inflation hovers around $1.7 \%$ in the last year of the sample. Price changes for food items primarily drive this pattern: the variance of these changes is large, and food items represent a sizable share of price changes. Other product categories have less frequent, mainly positive price adjustments. This finding support the idea that at least two product categories are required in macroeconomics models to be consistent with the empirical distribution of price changes. To produce the long tails, I need a category of items whose magnitude of price changes has a large variance. When mixed with a category displaying less variable and mainly positive changes, an asymmetry around zero could arise.

\footnotetext{
${ }^{22}$ The distribution is conditional on observing a price change such that its density integrates to one. Prices from all nonregulated product categories are used to construct the graphs.
} 
Finally, I find a clear effect of changes in the VAT on the distribution of price changes. The two middle graphs show the distribution when the 5\% VAT hike occurred in April 1995. The density of the interval comprising the mode of the distribution stands out as unusually and falls within the band corresponding to the change in the VAT.

\subsection{Sector Frequencies}

Similar to the findings for the United States and Euro area, a substantial heterogeneity in consumer price stickiness exists across major product groups in Mexico (see Figure 9). ${ }^{23}$ In particular, Foods and nonalcoholic beverages stands out for its high frequency of price changes and the prevalence of price decreases. Its frequency averages $41.4 \%$ over the last three years of the sample when inflation was low, a percentage almost identical to its $41.8 \%$ average over the full sample period; in contrast, the average frequency of other groups is generally half of those numbers or less. The share of price decreases for Food and nonalcoholic beverages is $35.8 \%$ over the full sample and $45.4 \%$ in the last three years. Other groups experience few or no price decreases over most of the sample period. Only when inflation settled comfortably below $10 \%$ did price decreases rise mildly. Given these observations, food products clearly are key to the importance of price decreases at the aggregate level.

Figure 9 also shows that almost every sector rapidly felt the inflationary pressure accompanying the devaluation. In January 1995, all groups but Education experienced a sharp rise in the frequency of price changes. A second wave of rapid increases in the frequency of price changes also surfaced in most groups in April 1995. The clear spikes in the series relate to a change in the value added tax, which I will discuss in greater detail at the end of the section.

I also find evidence of seasonality in the timing of price changes for groups containing a large proportion of services. In particular, Health, Restaurants and Hotels as well as Transportation display some seasonality in January. Education is a stricking case, with more than 90\% its prices changing in either August or September and few if any prices changing at other times of the year. These seasonal patterns can be considered as a form of time dependence in which prices are adjusted at fixed time intervals. The strong seasonality particuliar to Education stems largely from the nature of the items it encompasses; tuition, registration fees and room and board in academic institutions constitute the bulk of observations in that category. These items are distinctive because both the price and quantity consumed are fixed for a certain time period (say, a semester or an academic year). In that sense, they differ from the staggered pricing model where the price is fixed but the quantity can fluctuate freely.

\footnotetext{
${ }^{23}$ To facilitate comparisions, I classify each product category according to the Euro area Classification Of Individual COnsumption by Purpose (COICOP). I report the results for 2-digit groups using all product categories unaffected by the 1995 basket revision, regardless of whether they are regulated or not. For Housing, water, electricity, gas and other fuels and Communications, I could not compute the frequency because of a lack of data.
} 


\subsection{Inflation Variance Decomposition}

In this section, I quantify the importance of fluctuations in the frequency and magnitude of price changes for the variance of inflation. The starting point is a first-order Taylor-series expansion of $\pi_{t}=f r_{t} d p_{t}$ around $\overline{f r}$ and $d p_{t}$, as implemented by Klenow and Kryvtsov (2005):

$$
\pi_{t}=\overline{f r} \cdot \overline{d p}+\overline{f r} \cdot\left(d p_{t}-\overline{d p}\right)+\overline{d p}\left(f r_{t}-\overline{f r}\right)+\left(d p_{t}-\overline{d p}\right)\left(f r_{t}-\overline{f r}\right)
$$

Taking the variance on both sides and collecting terms, one obtains

$$
\operatorname{var}\left(\pi_{t}\right)=\underbrace{\overline{f r}^{2} \cdot \operatorname{var}\left(d p_{t}\right)}_{T D P}+\underbrace{\overline{d p}^{2} \cdot \operatorname{var}\left(f r_{t}\right)+2 \overline{f r \cdot d p \cdot} \operatorname{cov}\left(d p_{t}, f r_{t}\right)+O_{t}}_{S D P}
$$

This expression provides a decomposition into a time dependent (TDP) and a state dependent (SDP) part. TDP is the only term depending solely on $d p_{t}$, whereas all terms in SDP, including the higher-order terms $O_{t}$, are functions of $f r_{t}$. In the Calvo model, as well as in the Taylor pricing model with uniform staggering, the TDP term accounts for all of the inflation variance. Finding non-zero terms in SDP therefore can serve as evidence against these time dependent models. Using U.S. CPI data for 1988-2003, Klenow and Kryvtsov find only a minor role for the terms in SDP, and around $95 \%$ of the variance in the monthly inflation series stem from fluctuations in $d p_{t}$. This aspect of the United States' recent inflation experience therefore conforms to time dependent models.

The figures for Mexico differ markedly from those for the United States. As shown in Table 3 , the TDP term represents only $42.5 \%$ of the inflation variance over the full sample period, leaving a much greater role for fluctuations in $f r_{t}$. This comes as no surprise given the high correlation between $f r_{t}$ and $\pi_{t}$ over the sample period. The smaller share of variance that the TDP terms account for also appears in both the goods and services sectors. This share is particularly small for services at $14.6 \%$, but this figure stems primarily from the strong seasonal pattern in the pricing of Education services. ${ }^{24}$ In the case of goods, movements in $f r_{t}$ also are important, with the notable exception of unprocessed food, which I will discuss shortly.

As I have shown, the high inflation episode drives the correlation between $f r_{t}$ and $\pi_{t}$, which becomes essentially zero as inflation levels off. This elusive relationship has a direct consequence for the variance breakdown. When restricted to the low-inflation period after mid-1999, the share of inflation variance represented by the TDP climbs to $83.5 \%$. This proportion reaches $95.1 \%$ when services are excluded, a figure comparable to Klenow and Kryvtsov's finding for the United States. In contrast, the proportion is lowest when inflation is most variable. The short subperiod before 1995 represents an intermediate case. Taken

\footnotetext{
${ }^{24}$ Although seasonality sometimes is interpreted as evidence of time dependency, it does not feed into the TDP term here because the benchmark assumes uniform staggering.
} 
together, these findings help indicate when time-dependent models have realistic implications for the inflation variance. As Figure 7 shows, there is a tight, almost linear relation between $d p_{t}$ and $\pi_{t}$ when the latter is below $10-15 \%$. This strong comovement drives the variance decomposition during the low-inflation period. Then, as inflation takes off, $f r_{t}$ becomes more positively correlated with $\pi_{t}$ and $d p_{t}$. This relationship induces a substantial role for terms involving $f r_{t}$, especially for the covariance and higher-order terms.

As noted earlier, the time-dependent part accounts for most of the variance of unprocessed food inflation, presumably because the frequency is high even when inflation is low. This finding means there is little room for the frequency to adjust when inflation takes off. I uncover support for this conjecture at the product category level: The TDP term accounts for a larger share of the variance in product categories with especially frequent price adjustments. ${ }^{25}$

\subsection{Effects of the VAT Change}

Changes to value added taxes are observable events that can reveal precious information about how an economy adjusts in response to such shocks. On April 1, 1995, the generate rate of the VAT rose from 10 to $15 \%$ everywhere in Mexico, with the exception of cities located in a corridor along the northern and southern borders, as well as the whole Baja California. Mexican retailers are required to include the VAT in their sales prices. All else equal, an increase in the VAT squeezed retailer's profit margins, thereby creating an incentive for adjusting prices upward. In TDP models, this adjustment occurs only through larger price changes. In this section, I investigate whether this prediction was actually realized.

Two features make the April 1995 VAT increase particularly interesting. First, retailers were given a very short notice of the VAT change. The decree was adopted March 18 and published in the Diario on March 27. A large number of price quotes for March 1995 were collected before the public learned of the change and the tax was in full force when collection started in April. Second, the change did not affect all items and cities. Prices from excluded groups of products and geographic areas can serve as controls to disentangle the effect of the VAT from other factors.

The results are presented in Figure 10. The sample was divided into four groups according to whether items are taxed rate or tax-exempt (respectively labelled "general rate" and "excluded items") and whether they are located in cities affected or unaffected by the change (labelled "Center" and "Border", respectively). Inflation rates, expressed in the graph as monthly rates, differed markedly across regions and goods in April 1995. The inflation rate of center cities exceeded the rate for border cities by 3.1 percentage points in the case of goods affected by the general rate. That same month, the difference was -1.2 percentage points

\footnotetext{
${ }^{25} \mathrm{~A}$ simple unweighted linear regression of the share of variancethe TDP term accounts for over the average item frequency has a slope of 0.86 for the full sample and 1.11 for the high-inflation period. Both slopes are significant at the $95 \%$ confidence level, and the respective $R^{2}$ are 0.58 and 0.78 .
} 
for goods exempted from the VAT. These differences clearly indicate that most of the price adjustment occurred within a month. Notably, the adjustment occurred mainly through more frequent rather than larger price changes. For the items taxed under the general rate, the fraction of price changes in April is $75.1 \%$ for the cities affected by the change, and $39.4 \%$ for the cities where the rate remained at $10 \%$. For items that are taxed-exempt, the frequency of price changes are very similar across regions where the tax rate increased $(47.9 \%)$ and where it did not $(49.3 \%)$. The average magnitude of price change is similar across regions, which might be surprising given that I previously noticed a spike in the price change distribution of items in cities affected by the change. The effect of the tax change on the average price increase was minute.

The sharp increase in the frequency of price changes was the main source of inflation pass-through. Direct proof of this conclusion appears at the bottom of Figure 10, where three inflation rates are reported. The first is the actual inflation rate for the cities affected by the tax; this rate is the product of the frequency and magnitude of price changes, $f r_{t}^{b o r d e r} \cdot d p_{t}^{b o r d e r}$. The other two series are obtained by replacing $f r_{t}^{b o r d e r}$ and $d p_{t}^{b o r d e r}$ by their respective values for cities along the borders. The three series are computed first for items under the general rate and then repeated for tax-exempt items. The predicted inflation rate is almost identical to the actual rate when I replace the magnitude of price changes. However, when I use the lower frequency of border cities, there is no increase in inflation.

Note that inflation rose more rapidly in border cities. This behavior is consistent with the greater exchange rate pass-through along the border. I found the difference in inflation to be particularly large for Food and nonalcoholic beverages and Restaurants and hotels. Although items in the latter category usually are classified as nontradables, the importance of tourism in border cities might have contributed to the greater pass-through.

Several authors have noted the effect of VAT changes on the frequency of price changes. ${ }^{26}$ The Mexican tax change is especially interesting, however, because of its unusually large size and the regional differences in its application. The change in the frequency, about 35 percentage points, is larger than any other documented frequency change. Furthermore, because price decreases were nearly absent in April 1995, one could conjecture that their buffering effect did little to prevent the aggregate frequency from rising. However, VAT hikes do not seem to be associated with unusually large falls in $f r^{-}$in Europe.

\footnotetext{
${ }^{26}$ Particularly for Spain (Álvarez and Hernando, 2004), Belgium (Aucremanne and Dhyne 2004a, 2004b), France (Baudry et al. 2004), Portugal (Dias, Dias and Neves 2004), Germany (Hoffmann and Kurz-Kim 2004) and the Netherlands (Jonker et al., 2004).
} 


\section{International Comparisons}

A priori, it is difficult to know how the findings for Mexico might generalize to other countries because there are no comparable studies with similar product and inflation coverage. In this section, I construct baskets of goods similar to the ones used for the low-inflation studies in the United States and Euro area studies. I also break down the Mexican sample into lowand high-inflation subperiods to provide more direct comparisons. In show that Mexico is an intermediate case between the United States and the Euro area in terms of price stickiness. I then compare my results with the sectoral studies done at high inflation.

\subsection{Low-Inflation Studies}

\subsubsection{Time and Product Coverage}

Three time periods of 24 months were selected. The first starts in March 1995, immediately after the CPI basket revision, and captures a period when inflation averaged nearly $30 \%$. The second period covers the last two years of data before the second revision of the CPI basket in 2002. The third period runs from January 2003 to December 2004. The inflation rate over the last two samples is only a few percentage-points higher than the United States and Euro area studies. The third period is the most directly comparable to the U.S. and Euro-area studies in terms of methodology and product coverage.

Statistics for the frequency of price changes are computed for two different baskets. The first, the BK basket, has a product coverage similar to the one Bils and Klenow (2004) used for the United States. Its construction was detailed in Section 2.2. ${ }^{27}$ This sample covers $69.8 \%$ of Mexican consumption expenditures before the 2002 revision of the CPI basket. In the third time period, I use all categories with individual observations, resulting in a CPI coverage of $77.9 \%$. In comparison, Bils and Klenow's sample covers $68.9 \%$ of U.S. consumption expenditures. To produce comparable statistics, I classified the Mexican product categories according to the BLS classification system used from 1989 to 1997.

The second basket matches the one used by the Inflation Persistence Network and is consequently labeled the IPN basket. This smaller basket is restricted to 50 product categories to facilitate comparisons across countries. Categories are representative of 2-digit groups in the Classification Of Individual COnsumption by Purpose (COICOP) and of the following five main components: unprocessed food, processed food, energy, nonenergy industrial goods (NEIG) and services. Details of the basket construction are relegated to Appendix C.

\footnotetext{
${ }^{27}$ It excludes all product categories introduced in March 1995; their price changes are not observed until July 1995 because the first four months of all price trajectories are cut during the filtering procedure. Excluding those categories has a negligible effect on the results after July 1995.
} 


\subsubsection{Results}

The results are presented in Table 4 . Because they are very similar for the BK and IPN baskets, I will focus on the broad findings. The CPI inflation rate averages $28.5 \%$ in Mexico over the first time period, a rate well above the $2.3 \%$ and $1.6 \%$ averages in the U.S. and Euro-area samples, respectively. Not surprisingly, the aggregate frequency of price changes is much higher in Mexico, averaging $32.3 \%$ in the BK sample, more than twice the Euro area average, and 20\% higher than the United States. The higher frequency is reflected in terms of shorter durations. The median duration in Mexico is about three months compared with 4.6 months in the United States and 10.6 months in the Euro area. I also report the average duration and the inverse of the aggregate frequency. Although both are sensitive to the underlying heterogeneity, they nevertheless confirm the previous ranking. Notably, the difference between the mean and the median declines considerably during the high-inflation period.

In the second and third time periods, Mexican inflation rates are much closer to their American and European counterparts than in the first time period. The frequency of price changes falls a few percentage points below that of the United States despite a slightly higher inflation rate, and it stops about eight to 10 percentage points higher than that of the Euro area. Overall, the Mexican economy appears less flexible than the U.S. economy and more flexible than the Euro-area economy for comparable inflation rates.

A higher aggregate frequency does not necessarily imply increased flexibility for prices at the product-category level, however. Indeed, differences in CPI composition may also play role because of the considerable heterogeneity at the sector level documented earlier. Table 5 reports the expenditure weights for major groups of products under the BLS and COICOP classifications. The weights represent the shares of the BK and IPN baskets each special group accounts for. The most striking difference is the relatively large share of Food in the Mexican consumption basket. In contrast, both Durable goods and Services account for smaller shares in Mexico than in the United States.

Table 6 provides frequency statistics for each special group. For the high-inflation period, the frequency of price changes for the Food, Home Furnishing, Medical Care and Others categories was higher in Mexico than the United States. ${ }^{28}$ As inflation leveled, the frequency remained higher for Food in Mexico, but was comparable to the United States or lower for all other categories. With respect to the Euro area, prices appear more flexible in Mexico for all observed inflation levels, and for all categories except Energy. The table also indicates how differences in composition affect the aggregate frequency of price changes. Holding the frequency of special groups constant, I computed the aggregate frequency that would have

\footnotetext{
${ }^{28}$ The special group Others includes tobacco and smoking products, personal care goods and services, personal services and educational expenses.
} 
resulted if Mexico had had the same category weights as the United States and Euro area. For the BK sample, using the U.S. weights for Mexico lowers its frequency from $32.3 \%$ to $28.7 \%$ for the high-inflation period and from $21.6 \%$ to $18.5 \%$ for the lowest inflation period. In the case of the IPN basket, the frequency would have dropped from 33.3 to $27.6 \%$ for the highinflation period. In short, the relatively large share of CPI expenditures for food, particularly unprocessed food, contributes to the overall flexibility of consumer prices in Mexico.

\subsection{High-Inflation Studies}

The amount of empirical evidence on the setting of consumer prices during high inflation is very limited. Lach and Tsiddon (1992) consider a sample of 26 food products in Israel (mainly meat and alcohol products). For the period 1978-79, 39.5\% of prices changed in their sample every month while the annual inflation rate averaged $60 \%$. This figure is almost the same as the average frequency of price changes for food products in my high-inflation sample (40.5\%), even though the average inflation rate in Mexico (28.5\%) was only half that of Israel. A related study featuring Konieczny and Skrzypacz (2005), who study the transition from a planned to a market economy in Poland. They use monthly data on 52 products, of which 37 are food products, from January 1990 to December 1996. They report a monthly frequency of price change of $59 \%$ as inflation peaked at $249 \%$ in 1990 . In contrast, the frequency of price changes was $30 \%$ in 1996 when inflation averaged 19\%. Interestingly, the frequency was only from 35\% in 1993 although inflation was double its 1996 rate (38\%). This finding supports the idea that movements in the frequency of price changes are dampened in the food sector due to the presence of price decreases. Burstein, Eichenbaum and Rebelo (2005) conduct a weekly survey of supermarket prices for a broader basket covering 58 good categories in Argentina from March to December 2002, when the annual inflation rate averaged $33 \%$. They find a $66.5 \%$ median frequency of price changes. This percentage is much larger than what I find for Mexico. Part of the difference is likely explained by differences in the type of outlets surveyed. $^{29}$

\section{Characterizing the Empirical Hazard}

So far, I have examined the connection between inflation and price setting at the aggregate level. In this section, I focus on the determinants of individual price changes. I particularly am interested in the probability of an individual price changing given that $\tau$ periods have elapsed since its last adjustment, a statistic commonly known as the hazard function of price changes. This function is a potentially useful tool for discriminating among the various pricing models outlined in the literature. Pricing models often have diverging implications for the

\footnotetext{
${ }^{29}$ Baudry and al. (2004) report that the outlet size is positively correlated with the frequency of price changes in French CPI data.
} 
hazard shape and determinants, and particularly for the incidence of inflation. Consider an environment, for example, with strictly positive inflation. In the generic Calvo model, the hazard function is constant. In Taylor's staggered pricing model, it is zero for the duration of the contract and one at expiration. In both cases, the hazard function is affected neither by inflation nor by other factors such as tax changes, marginal cost shocks, demand shifts, etc. In contrast, the state-dependent models of Dotsey, King and Wolman (1999) and Golosov and Lucas (2003) imply a hazard that is a strictly increasing function of the time elapsed since the last price change.

The main challenge in the estimation is properly accounting for the underlying heterogeneity across individual items: Items with intrinsically high price-change frequencies are overrepresented among short durations and underrepresented among long durations. Ignoring this selection effect will lead to a downward bias for the estimated slope of the hazard, a serieous concern because unobserved factors like marketing practices, variations in the size of the menu cost, the degree of local competition or seasonal variation in supply or demand can affect the intrinsic rate at which the item price changes. ${ }^{30}$ I address this problem by modeling the probability of an individual price change using Chamberlain's conditional fixed-effects logit. This specification allows for unobserved heterogeneity in the level of the hazard across items. The time elapsed and the amount of cumulative inflation since the last price change are included among the regressors, making it possible to use the logit estimates to compute a hazard function at different time horizons and inflation levels.

\subsection{The Econometric Model}

The probability of observing a price increase is modeled as follows

$$
\operatorname{Pr}\left(I_{i t}^{+}=1 \mid x_{i, t}\right)=\frac{e^{\alpha_{i}+x_{i, t} \beta^{\prime}}}{1+e^{\alpha_{i}+x_{i, t} \beta^{\prime}}}
$$

where $I_{i t}^{+}$indicates the occurence of a price increase, $\alpha_{i}$ is an item-specific fixed-effect and $x_{i, t}$ is a vector of regressors. The probability of observing a price decrease is similarly specified, and the probability of observing a price change is computed as the sum of $\operatorname{Pr}\left(I_{i t}^{+}=1 \mid x_{i, t}\right)$

\footnotetext{
${ }^{30}$ Álvarez, Burriel and Hernando (2005) consider an environment where heterogeneous price setters follow rules as in the Calvo, truncated Calvo, Taylor contracts or Dotsey, King and Wolman specifications. They show analytically that the estimated aggregate hazard almost always decreases the estimation does not account for heterogeneity.
} 
and $\operatorname{Pr}\left(I_{i t}^{-}=1 \mid x_{i, t}\right)$. The time-varying component $x_{i t} \beta^{\prime}$ is given by

$$
\begin{aligned}
& x_{i, t} \beta^{\prime}=\sum_{n \in\{2, \ldots, 12\}} \beta_{1, n} \text { Mont }_{n, t}+\sum_{n \in\{1994, \ldots, 2001\}} \beta_{2, n} \text { Year }_{n, t}+\sum_{n \in\{1,3,6,12,24\}} \beta_{3, n} \text { Taylor }_{n, t} \\
& +\sum_{n \in\{0,1,2\}} \beta_{4, n} V A T_{n, t}+\sum_{n=1}^{2} \beta_{5, n}\left(T_{t}\right)^{n}+\sum_{n=1}^{2} \beta_{6, n}\left(\pi_{t}^{\mathrm{sec}}\right)^{n}+\sum_{n=1}^{2} \beta_{7, n}\left(C u m \pi_{t}^{\mathrm{sec}}\right)^{n}
\end{aligned}
$$

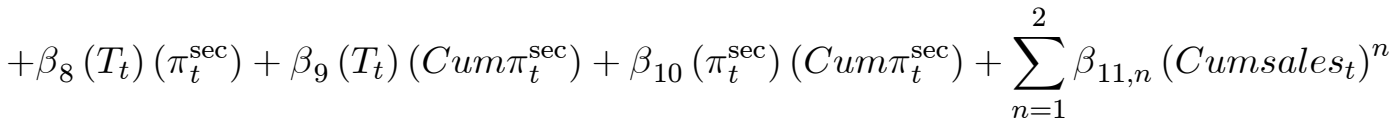

$$
\begin{aligned}
& +\beta_{12} L d p d w_{t}+\sum_{n=1}^{2} \beta_{13, n}\left(L d p d w_{t}\right)\left(\text { Lastd }_{t}\right)^{n}+\sum_{n=1}^{2} \beta_{14, n}\left(1-L d p d w_{t}\right)\left(\text { Lastup }_{t}\right)^{n}
\end{aligned}
$$

where the regressors are

\begin{tabular}{ll}
\hline Month $_{n, t}$ & Month dummies \\
Ear $_{n, t}$ & Year dummies \\
Taylor $_{n, t}$ & Indicator that last price change occurred $n$ months ago \\
A $_{n, t}$ & Indicator that VAT change occurred $n$ months ago \\
$T_{t}$ & Number of months since last price change \\
$\pi_{t}^{\mathrm{sec}}$ & Sectoral inflation \\
Cum $_{t}^{\mathrm{sec}}$ & Cumulated sectoral inflation since last price change \\
Ldpdw $_{t}$ & Indicator that last price change was a decrease \\
Lastdw $_{t}$ & Absolute magnitude of last price decrease (in logs) \\
Lastup $_{t}$ & Absolute magnitude of last price increase (in logs) \\
Cumsales $_{t}$ & Cumulative change in retail sales index \\
\hline
\end{tabular}

The month dummies capture seasonal variation in the frequency of price changes. Year dummies control for variation over time that other regressors do not account for. In particular, they could captures variation in methodology over the sample period. The Taylor dummies indicate that the last price change occurred one, three, six, 12 and 24 months ago. These dummies are introduced to verify if individual prices are adjusted at fixed durations, as is the case in the Taylor price staggering model. Finding a significant role either for the month or Taylor dummies would be consistent with time-dependence in the data. The regressors also include the time elapsed since the last price change, $T_{t}$, the current level of inflation at the product category level, $\pi_{t}^{\mathrm{sec}}$, the amount of cumulated inflation since the last price change, $C u m \pi_{t}^{\mathrm{sec}}$, as well as their second-order (cross) terms. Those variables, along with the Taylor dummies, are used to compute the hazard function at different time horizons and inflation levels. I include the cumulative percentage change in an index of retail sales to proxy for 
changes in aggregate demand. ${ }^{31}$ Finally, I incorporate terms accounting for the sign and magnitude of the last price change.

The methodology adopted in this paper is similar to Cecchetti (1986), and the set of regressors borrows from Aucremanne and Dhyne (2005). Although the approach is reduced-form, theoretical considerations guide the choice of regressors. In the menu-cost model considered by Sheshinski and Weiss (1977 and 1983), the optimal pricing policy of a firm is $(s, S)$; whenever the distance between the current and optimal frictionless prices falls below $s$, the fixed cost is incurred, and the distance is reset to $S$. Ceccetti relates this distance to the time elapsed since the last price adjustment, the amount of cumulated inflation and the change in aggregate demand. In a more general environment where both positive and negative price changes are possible, price adjustment occurs whenever the current price is either too large or too small. ${ }^{32}$ The sign and magnitude of the previous price change must be included among the regressors because they carry information regarding the distance between the current and optimal prices. Finally, to account for the possibility that current economics conditions affect the $(s, S)$ policy, I also include in the estimation the current level of sectoral inflation in the estimation. ${ }^{33}$

Note that the fixed-effects, $\alpha_{i}$, are not estimated in Chamberlain's conditional logit. This situation creates a practical problem when reporting the hazard function, as this function depends on the value of $\alpha_{i}$. To compute the hazard at some meaningful level of the fixed effect, I first estimate $\beta$ using the fixed-effects logit. For each price trajectory, I then compute the fixed effect $\alpha_{i}$ that maximizes the likelihood conditional on $\hat{\beta}$. In the case of price increases,

$$
\hat{\alpha}_{i}=\arg \max \prod_{t=t_{0, i}}^{T_{i}} \operatorname{Pr}\left(I_{i t}^{+} \mid x_{i, t}, \hat{\beta}\right)^{I_{i t}^{+}}\left(1-\operatorname{Pr}\left(I_{i t}^{+} \mid x_{i, t}, \hat{\beta}\right)\right)^{1-I_{i t}^{+}} .
$$

I finally set $\alpha_{i}$ to equal to the weighted median of the distribution of fixed effects. ${ }^{34}$ Whether the hazard is an increasing or decreasing function of time or inflation is independent of the particular choice of $\alpha_{i}$. The estimation is carried separately for each 2-digit COICOP group to

\footnotetext{
${ }^{31}$ The series is called Index of net retail sales in real terms and is published by INEGI. I use the subindex for food in the case of unprocessed and processed food items, and the general index for nonenergy industrial goods and services items.

${ }^{32}$ Ceccetti does not consider this possibility because his sample contains no price decreases. If price decreases had been present, the econometric model his approach implies would have been an ordered logit with fixedeffects. Because of inherent computational challenges in estimating such model with a large dataset, I instead estimate a fixed-effects logit on price increases and decreases separately. This alternative approach is consistent but may not be efficient.

${ }^{33}$ The hazards are similar when aggregate inflation is used rather than inflation at the product category level. An exception is unprocessed food for which the proportion of price decreases is larger at low inflation; this pattern arises because of a downward trend in the relative price of unprocessed food with respect to the CPI.

${ }^{34}$ Each trajectory within a product category is equally weighted. The sum of weights in each category corresponds to the category's relative share of CPI expenditures.
} 
allow variation in the coefficients. Up to 5,000 price trajectories are randomly selected within each group. I do not consider trajectories shorter than 36 months in the randomization. The hazard for price changes is then obtained by summing the hazard for price increases and decreases. The hazard functions are reported for steady annual inflation levels of $0,10,20$ and $30 \%$ and a baseline specification of the other regressors. ${ }^{35}$

\subsection{Estimation Results}

A quick look at the coefficients in Table 7 indicates that time and state dependent features of the data significantly affect the probability of observing a price change. Time dependence manifests itself partly through the significance of most of the Taylor dummies. The dummies at 1 and 12 months have a significantly positive effect on the probability of observing a price change for most groups. The particularly large increase after a month partly reflects the presence of temporary sales and could also captures the transcription errors of CPI price collectors (Such mistakes create spurious price changes that are corrected the next time a CPI agent visits the store). Some of the month dummies also significantly differ from zero, but their effect is relatively small compared with that of Taylor dummies (not shown here).

Although finding a significant role for the month or Taylor dummies suggests timedependence, prices alternatively could be responding to states with a seasonal component. For example, the seasonal nature of agricultural production affects the supply of fresh food. On the demand side, the level of retail sales, from which the regressor Cumsalest is derived, is strongly cyclical; on average, retail sales are about $40 \%$ higher in December than in other months of the year. Despite these large variations, however, the effect of changes in retail sales seems primarily second order.

Clear evidence of state-dependence is found with respect to the sign and magnitude of the previous price change. The previous occurrence of a price decrease significantly raises the probability of observing a price increase and typically makes another price decrease less likely. For all groups, large price decreases are less likely than small ones to be followed by another price decrease. Following a large price decrease, a price increase is significantly more likely to occur for both processed food and non-energy industrial goods. The effect is reversed, however, for unprocessed food. The reason behind these opposite effects could be that price decreases are associated mainly with temporary sales in the case of processed food and nonenergy industrial goods and with seasonal price movements in the case of unprocessed food. Overall, this evidence is consistent with the findings of Campbell and Eden (2005) that large price deviations tend to be short lived.

The level of inflation, the amount of cumulative inflation and the time elapsed since the last price change all significantly affect the probability of observing a price increase or de-

\footnotetext{
${ }^{35}$ In the baseline hazard, the reference year is 2002, and the month effects are averaged. The last price change is assumed to be an $8 \%$ increase. Changes in cumulative sales and the value added tax are set to zero.
} 
crease. Second-order and cross terms complicate the interpretation of coefficients, however. Figures 11 and 12 show more direct evidence of these factors' effect by reporting the hazard functions along with $95 \%$ pointwise confidence intervals. ${ }^{36} \mathrm{~A}$ visible effect of inflation is to shift the level of the hazard function of price increases and decreases in opposite directions, thereby dampening the effect on the hazard of price changes; this is the item-level equivalent of the offsetting effect previously found at the aggregate level. The offsetting effect is particularly strong for unprocessed food, keeping the frequency of price changes roughly constant as inflation varies from 0 to $30 \%$. For processed food and nonenergy industrial goods, on the other hand, the offsetting effect is much weaker: Few price decreases occur in those groups when inflation reaches $10 \%$. The group of services stands alone because price decreases are rare in the sample even at low inflation rates. ${ }^{37}$

For high enough inflation rates, the hazard function is increasing over the first 12 months for processed food and non-energy industrial goods. Although the hazard also increases rapidly for services at horizons longer than a year (not displayed here), the width of the confidence bands increase even more rapidly. Increasing hazards, a prediction of menu-cost models, therefore find some support in the Mexican data. The level of inflation for which the hazard increases is higher than in Aucremanne and Dhyne (2004), who report evidence of increasing hazards in Belgian CPI data at levels of inflation as low as a few percentage points above zero. A potential explanation for this difference could be different treatment of temporary sales: The Belgium CPI does not account for rebates and temporary promotions related to winter and summer sales. Another explanation, consistent with the offsetting role of price decreases, is Belgium's greater price stickiness, particularly for non-energy industrial goods and services. ${ }^{38}$ Few price decreases could signify that the hazard of price changes inherits the more upward-sloping trend of the hazard of price increases at lower inflation levels.

Lastly, the hazard of price changes sometimes is found to be a decreasing function of time. This negative duration dependence surfaces for unprocessed and processed food items, and it is particularly strong over the first few months and at low inflation levels. Negative duration dependence is consistent with results from Campbell and Eden (2005), who report decreasing hazards over the first 12 weeks in scanner data even after controlling for sales as well as store and UPC fixed effects. It is at odds with almost every price-setting model in the macroeconomic literature, however. ${ }^{39}$ I cannot exclude that marketing practices, temporary

\footnotetext{
${ }^{36}$ The confidence intervals are computed using the delta method conditional on the value of the median fixed effect. To compute the confidence band for the hazard of price changes, I assume no covariance between the estimates of the hazard for price increases and decreases.

${ }^{37}$ The hazard of price decreases is exactly zero for services in Figure 11. Most price trajectories do not contain any price decreases, resulting in a median fixed effect of $-\infty$.

${ }^{38}$ The average frequency of price changes for nonenergy industrial goods and services of reported by Aucremanne and Dhyne (2004) are $7.4 \%$ and $5.9 \%$, respectively.

${ }^{39}$ One exception is Rotemberg's (2004) fair pricing model, which is consistent with temporary sales.
} 
sales, or seasonality in the adjustment of prices.

\subsection{Specification Checks}

The fixed effect in the logit substantially reduce the downward bias in the slope of the hazard function compared with a logit without fixed-effects, even after accounting for city and product category effects (not reported here). Dropping all second-order terms leads to similar results, but this simpler specification lacks the flexibility to account for the decline in the hazard during the first few months. Adding higher-order terms did not generate in any qualitative changes, except at horizons longer than 12 months for which there are few observations. As an alternative to the fixed-effects logit, I also estimated a random-effects logit. City and

product category dummies were added to the regressors to account for some of the underlying heterogeneity. Although this specification produces similar hazard functions at low inflation levels (not reported here), the slopes it generates at high inflation levels are less positive than in the fixed-effects logit. Ultimately, the fixed-effects logit was preferred over the randomeffects logit because the latter requires the error term to be uncorrelated with the regressors. This assumption likely would be violated because a large realization of the random effect, associated with an intrinsically high frequency of price changes, would tend to be correlated with the time elapsed since the last price change and the amount of cumulated inflation.

\section{Implications for Price Setting Models}

In this section, I discuss the strengths and shortcomings of several established pricing models in light of my findings. Because of space constraints, I focus on select time-dependent models and state-dependent models of menu-cost. Although the models I address compose only a subset of the numerous price-setting models in the literature, the discussion highlights the main features that successful models should exhibit.

Time-dependent models, like the generic Calvo and Taylor staggered pricing models, clearly fail to match the variability of the frequency of price changes over time in my dataset. Movements in the frequency of price changes not only were large but also accounted for a nonnegligible share of the inflation variance over my sample period. The VAT change experiment is a stunning example of a shock for which time-dependent models cannot generate realistic dynamics: The price adjustment occurred entirely through a change in the frequency rather than in the magnitude of price changes, which time-dependent models wrongly assume. With the exception of services, staggered pricing models seem particularly poorly supported by the data. The hazard function of nonregulated goods shows little clustering of price durations at specific horizons. Even in the case of services, where there is evidence of frequent price resetting in January and September, substantial uncertainty surrounds the occurrence of price 
changes.

Despite its shortcomings, the generic Calvo model approximates at first glance some central features of the Mexican data. Below 10-15\% inflation, movements in the frequency of price changes of nonregulated goods are small and show no correlation with inflation. Consequently, the relationship between the average magnitude of price changes and inflation is tight and linear, as the Calvo model assumes. As a result, movements in the frequency account for very little of the inflation variance. However, these observations do not lead automatically to the conclusion that movements in the frequency are unimportant at low inflation levels. On the contrary, the muted response of the frequency of price changes depends on an offsetting effect, which entails opposite movements in the frequencies of price increases and decreases.

To succeed in both low- and high-inflation environments, pricing models must allow the frequency of price changes to respond to inflation. In Dotsey, King and Wolman (DKW, 1999), firms randomly draw a menu-cost of changing their price from a distribution every period. All firms face the same marginal cost, and as long as inflation is strictly positive, these assumptions generate a distribution of positive price changes. There is no offsetting effect at low inflation levels because price decreases are absent in the model. Not surprisingly, the frequency of price changes responds too strongly to inflation, as shown by Klenow and Kryvtsov in their calibration of DKW to the U.S. economy. The share of inflation variance represented by the time-dependent part (see Section 5.5) is only about 20\%. This percentage is far below the empirical value for the United States (95\%), or Mexico at low inflation levels $(84 \%)$, and even lower than the percentage I find over my high and volatile inflation period (36\%). How the introduction of price decreases in DKW could improve its predictions remains to be investigated.

Gertler-Leahy (2005) recently suggested a tractable menu-cost model that partly addresses the excess variability of the frequency. Borrowing from the Golosov-Lucas model discussed below, they assume firms are subject to idiosyncratic marginal cost shocks while facing a constant menu cost of changing their price. This situation gives rise to a distribution of both positive and negative price changes. Aggregate shocks are small relative to idiosyncratic shocks, so only idiosyncratic shocks trigger price adjustments. Idiosyncratic shocks arrive randomly and at a constant rate. As a result, the frequency of price does not display the counterfactually large variance found in DKW at low inflation rates. Although this model offers an alternative to Calvo in low-inflation economies, its applicability to episodes like the Tequila crisis is severely limited. ${ }^{40}$

The state-dependent model of Golosov-Lucas (2003) addresses both low- and high-inflation episodes. This model is solved using global approximation methods. In this model, firms face the same menu cost while differing in their marginal cost, which is assumed to follow a

\footnotetext{
${ }^{40}$ The model is solved using a linearization around a zero-inflation steady state. This fact, along with the assumption that firms ignore macroeconomic shocks, limit the model's usefulness at high inflation levels.
} 
diffusion process. These assumptions give rise to both price increases and decreases and the model therefore embeds an offsetting effect at low inflation. One implication of the constant menu cost assumption is that price increases and decreases should cluster around particular values. The distributions of price changes that I report in Figure 8 do not support this prediction, however, as both small and large price changes are common. Another implication of this model is that price changes come from firms whose price has drifted furthest from their optimal frictionless price. This selection effect leads to small, short-lived, real responses to monetary shocks even at low inflation, thereby deviating from the main view in the literature on the United States (e.g., Mankiw, 2001, and Christiano et al., 1999). It remains to be

explored the extent to which the addition of heterogeneous menu costs to the Golosov-Lucas model to provide a better match of the distribution of price changes would increase the model's intrinsic persistence.

\section{Conclusion}

This paper provides new evidence about the relationship between inflation and the adjustment of individual consumer prices. It uses a large dataset of Mexican consumer prices covering episodes of both low and high inflation, as well as the transition between the two. The overall portrait is of an economy sharing several characteristics of time dependent models when inflation is low (below 10-15\%), while displaying strong state dependence when inflation is high (above 10-15\%).

At low inflation levels, the frequency of price changes varies little and its relationship to inflation is elusive. In contrast, the average magnitude of price change covaries strongly with inflation. As a result, movements in the frequency account for little of the inflation variance of inflation. Thus, at low inflation levels, the economy resembles time-dependent models with a constant frequency of price changes. When annual inflation runs above 10$15 \%$, however, inflation becomes positively correlated with the frequency of price changes: A one percentage-point increase in the annual inflation rate is associated with a $0.40-0.45-$ percentage-point increase in the frequency of price changes. Variations in both the frequency and magnitude of price changes are key in determining the variance of inflation. In this sense, my analysis provides a natural distinction between low- and high-inflation environments: In a low-inflation environment, price decreases matter.

Behind the radically different behaviors of the low- and high-inflation economies lies the central role of price decreases. As inflation varies, opposite movements in the frequency of price decreases offset movements in the frequency of price increases. When inflation is low, this mechanism is strong enough to render the frequency of price changes of nonregulated goods unresponsive to movements in inflation. When inflation is high, however, too few price decreases are left to counterbalance movements in the frequency of price increases. In this 
situation, the economy displays strong state dependence with respect to inflation.

Several authors (e.g., Dhyne et al., 2005) have argued that macroeconomics models should incorporate at least two sectors. The first sector, which corresponds to food products in Mexico, features very flexible prices that respond to frequent idiosyncratic shocks. The other sectors encompass a greater degree of price stickiness to capture items with infrequent and lumpy price adjustments. My analysis reinforces this view by showing the central role of price decreases in the dynamic of inflation in the sectors displaying the largest price flexibility.

Finally, my analysis suggests the "right" price-setting model might depend importantly on the characteristics of the shock at hand. I documented that a hike in the value added tax led to an almost complete pass-through after one month, most of which occurred through a high frequency of price changes. The speed of transmission was much higher than the speed commonly assumed for monetary and technology shocks. Price-setting models generating highly persistent responses to all types of shocks would mispredict the price adjustment entirely.

\section{References}

[1] Ahlin, Christian and Mototsugu Shitani. "Menu Costs and Markov Inflation: A Theoretical Revision with New Evidence", mimeo, Vanderbilt University, April 2005.

[2] Álvarez, Luis J., Pablo Burriel and Ignacio Hernando. "Do Decreasing Hazard Functions for Price Changes Make Any Sense?", ECB Working Paper Series No. 461, March 2005.

[3] Aucremanne, Luc and Emmanuel Dhyne. "How Frequently Do Prices Change? Evidence Based on the Micro Data Underlying the Belgian CPI", ECB Working Paper Series No. 331, 2004.

[4] Aucremanne, Luc and Emmanuel Dhyne. "Time dependent versus State dependent Pricing: A Panel Data Approach to the Determinants of Belgian Consumer Price Changes.", ECB Working Paper Series No. 462., 2005.

[5] Baharad, Eyal and Benjamin Eden. "Price Rigidity and Price Dispersion: Evidence from Micro Data", Review of Economic Dynamics Vol 7, pp. 613-641, 2004.

[6] Baudry, L., Le Bihan H., Sevestre, P. and S. Tarrieu. "Price Rigidity in France: Evidence from Consumer Price MicroData", ECB Working Papers Series No. 384, 2004.

[7] Bils, Mark and Peter J. Klenow. "Some Evidence on the Importance of Sticky Prices", Journal of Political Economy, vol. 112, no. 5, 2005.

[8] Burstein, Ariel. "Inflation and output dynamics with state-dependent pricing decisions", forthcoming, Journal of Monetary Economics, 2005. 
[9] Burstein, Ariel, Martin Eichenbaum and Sergio Rebelo. "Large Devaluations and the Real Exchange Rate", forthcoming, Journal of Political Economy, 2005.

[10] Caballero, Ricardo J., Eduardo M.R.A. Engel and Alejandro Micco. "Microeconomic Flexibility in Latin America", unpublished manuscript, Yale University, March 2004.

[11] Calvo, Guillermo. "Staggered Prices in a Utility Maximizing Framework", Journal of Monetary Economics No. 12, pp. 383-398, 1983.

[12] Campbell, Jeffrey R. and Benjamin Eden. "Rigid Prices: Evidence from U.S. Scanner Data", Federal Reserve Bank of Chicago, WP 2005-08, October 2005.

[13] Castellanos, Sara C., Rodrigo García Verdú and David S. Kaplan. "Nominal wage rigidities in Mexico: Evidence from Social Security Records", Journal of Development Economics, No. 75, pp. 507-533, June 2004.

[14] Chari, V.V., Patrick J. Kehoe and Ellen R. McGrattan. "Can Sticky Price Models Generate Volatile and Persistent Real Exchange Rates?", Review of Economic Studies, Vol. 69, No. 242, pp. 533-563, August 2002.

[15] Cecchetti, S.G. "The Frequency of Price Adjustment: a Study of Newsstands Prices of Magazines", Journal of Econometrics, no. 106, pp 683-708, 1986.

[16] Christiano, Lawrence J., Martin Eichenbaum and Charles Evans. "Monetary Policy Shocks: What Have We Learned and to What End?", Handbook of Macroeconomics, John B. Taylor and Michael Woodford (eds.) 1999.

[17] Christiano, Lawrence, Martin Eichenbaum, and Charles Evans. "Nominal Rigidities and the Dynamic Effects of a Shock to Monetary Policy", Journal of Political Economy, Vol. 113, No. 1, pp. 1 -45, 2005.

[18] Dhyne, Emmanuel et al. "Price setting in the euro area: Some stylised facts from Individual Consumer Price Data", ECB Working Paper Series No. 524, September 2005.

[19] Dornbusch, Rudiger and Alejandro Werner. "Mexico: Stabilization, Reform, and No Growth", Brookings Papers on Economic Activity, no. 1, pp. 253-97, 1994.

[20] Dotsey, M., King R. G., and A. L. Wolman. "State dependent Pricing and the General Equilibrium Dynamics of Money and Output", Quarterly Journal of Economics, Vol. 114, pp. 655-690, 1999.

[21] Eden, Benjamin. "The Adjustment of Prices to Monetary Shocks When Trade is Uncertain and Sequential", Journal of Political Economy, vol. 102, pp. 493-509, 1994.

[22] Eden, Benjamin. "Inflation and Price Adjustment: An Analysis of Microdata", Review of Economic Dynamics, no. 4, pp. 607-636, July 2001.

[23] Edwards, Sebastian. "The Mexican Peso Crisis: How Much Did We Know? When Did We Know It?", NBER Working Paper 6334, December 1997. 
[24] Edwards, Sebastian and Miguel A. Savastano. "The Morning After: the Mexican Pesos in the Aftermath of the 1994 Current Crisis", NBER Working Paper 6516, April 1998.

[25] Eichenbaum, Martin and Jonas D.M. Fisher. "Evaluating Calvo-Style Sticky Price Models", mimeo, Northwestern University, March 2005.

[26] Fougère, D, H. Le Bihan and P. Sevestre. "Heterogeneity in Consumer Price Stickiness: A Microeconometric Investigation", ECB Working Paper Series No. 536, October 2005.

[27] Galí, Jordi and Mark Gertler. "Inflation dynamics: A structural econometric analysis", Journal of Monetary Economics No. 44, pp.195-222, 1999.

[28] Gertler, Mark and John Leahy. "A Phillips Curve with An Ss Foundation", mimeo, New York University, April 2005.

[29] Golosov, Michael and Robert E. Lucas, Jr. "Menu Costs and Philips Curves", NBER Working Paper 10187, January 2005.

[30] INEGI. "Síntesis metodológica de la Encuesta Nacional de Ingresos y Gastos de los Hogares", various editions.

[31] Kashyap, Anil. "Sticky Prices: New Evidence from Retail Catalogs", Quarterly Journal of Economics, pp. 245-274, 1995.

[32] Klenow, Peter and Oleksiv Kryvtsov. "State-Dependent or Time-Dependent Pricing: Does It Matter for Recent U.S. Inflation?", NBER Working Paper no. 11043, January 2005.

[33] Konieczny, Jerzy D. and Andrzej Skrzypacz. "Inflation and Price Setting in a Natural Experiment", Journal of Monetary Economics, vol. 52 no. 3, April 2005.

[34] Lucas, Robert E., Jr. "Some international evidence on output-inflation tradeoffs", American Economic Review Vol. 63 No. 3, pp. 326-334, 1973.

[35] Lucas, Robert E. Jr. and Micheal Woodford. "Real Effects of Monetary Shocks in an Economy with Sequential Purchases", NBER Working Paper No. 4250, January 1993.

[36] Maćkowiak, Bartosz and Mirko Wiederholt. "Optimal Sticky Prices Under Rational Inattention", mimeo, Humboldt University in Berlin, July 2005.

[37] Mankiw, Gregory. "The Inexorable and Mysterious Tradeoff Between Inflation and Unemployment", Economic Journal, vol. 111, pp. 45-61.

[38] Mankiw, Gregory and Ricardo Reis. "Sticky Information Versus Sticky Prices: A Proposal To Replace The New Keynesian Phillips Curve", Quarterly Journal of Economics, vol. 117(4), pp. 1295-1328, 2002.

[39] OECD. "Economic Surveys: Mexico 1999/2000", Economic Surveys, no. 13, pp. 1-173, 2000. 
[40] Rotemberg, Julio J. "Customer Anger at Price Increases, Time Variation in the Frequency of Price Changes and Monetary Policy", NBER Working Paper 9320, November 2002.

[41] Rotemberg, Julio J. "Fair Pricing", NBER Working Paper 10915, November 2004.

[42] Sheshinski, Eytan and Yoram Weiss. "Optimum Pricing Policy Under Stochastic Inflation". Review of Economic Studies, vol. 50 no. 3, pp. 513-529, July 1983.

[43] Sims, Christopher A. "Implications of Rational Inattention", Journal of Monetary Economics, vol. 50, pp. 665-690, 2003.

[44] Smets, Frank and Rafael Wouters. "Comparing Shocks and Frictions in US and Euro Area Business Cycles: A Bayesian DSGE Approach", CEPR Working Paper No. 4750, November 2004.

[45] Taylor, John B. "Aggregate Dynamics and Staggered Contracts", Journal of Political Economy, No. 88, pp. 1-24, February 1980.

[46] Taylor, John B. "Staggered Price and Wage Setting in Macroeconomics", Handbook of Macroeconomics, John B. Taylor and Michael Woodford (eds.), 1999.

\section{Appendix A: Price Averaging}

In Mexico, price collectors visit outlets four times every month to collect prices of food items, and they visit twice per month to collect prices for all other items. The prices published in the Diario are an average of the prices collected over the month. In this appendix, I first discuss how observing a price's average rather than its actual value complicates inferences about the timing and magnitude of price changes. I then describe how I filtered the data to make the results in this paper more directly comparable to results from studies using prices collected once per month.

\section{A.1 Effects of Averaging on Frequency and Magnitude}

Suppose a price collector observes the price of an item twice every month and then computes two time series. The first is a simple average of the prices collected over the month (the average-price series). The other contains the second price collected each month (the point-intime series). The average-price series corresponds Banxico's current method, whereas pointin-time series are used in the United States and Euro area.

Changes to the average-price series typically are more frequent and of a smaller magnitude than changes to the point-in-time series. To illustrate this point, consider a price that is constant over the months $t-1, t$ and $t+1$, with the exception of a single adjustment at month $t$. If the price changes before the first price is collected at $t$, then both prices collected over that month equal the new price. Thus, the average- and point-in-time series are identical 
and correctly reflect the timing and magnitude of the actual price change. If the price change occurs between the two price collections, the point-in-time series still accurately represents the actual price. The average-price series, on the other hand, now displays two price changes: one at month $t$ and one at $t+1$. The average-price series records a second price change because the average price at $t$ has increased by only half of the change in the actual price. Finally, if the price adjustment occurs after the second collection, both the average price and point-in-time series display a change of the correct magnitude but with a one-month lag. ${ }^{41}$

\section{A.2 Filtration of Average Price Trajectories}

In the above example, a price change detected at the second price collection created two consecutive price changes of equal magnitude in the average-price series. My strategy entails finding such patterns and constructing a trajectory for the last price collected over the month that matches the average price and minimizes the number of price changes.

\section{A.2.1 Two consecutive price changes}

Let $p_{t}^{i}$ be the unobserved $i-t h$ price of an item for which collection happens twice a month, and let $\bar{p}_{t}=\left(p_{t}^{1}+p_{t}^{2}\right) / 2$ be its observed monthly average. Consider the case of two consecutive price changes starting at month $t$. (Additional price changes might precede or follow them.) If

$$
\bar{p}_{t}=\frac{\bar{p}_{t+1-} \bar{p}_{t-1}}{2}
$$

then I can construct a bimonthly sequence $\left\{\left(p_{\tau}^{1}, p_{\tau}^{2}\right)\right\}_{\tau=t-1}^{t+1}$ consistent with the observed average price sequence $\left\{\bar{p}_{\tau}\right\}_{\tau=t-1}^{t+1}$ that features no price change at $t+1$. I simply set $p_{t-1}^{i}=\bar{p}_{t-1}$ and $p_{t+1}^{i}=\bar{p}_{t+1}$, and assume the price change occurred between the two price collections at $t$ so that $p_{t}^{1}=\bar{p}_{t-1}$ and $p_{t}^{2}=\bar{p}_{t+1}$. The point-in-time sequence using the last price collected each month, $\left\{p_{t-1}^{2}, p_{t}^{2}, p_{t+1}^{2}\right\}$, features no price changes at $t+1$.

Similarly, consider an item whose price is collected four times per month. If

$$
\bar{p}_{t}=\frac{\left(5-d_{t}\right) \bar{p}_{t-1}+\left(d_{t}-1\right) \bar{p}_{t+1}}{4}
$$

for some $d_{t} \in\{2,3,4\}$, I can construct a sequence $\left\{\left(p_{\tau}^{1}, p_{\tau}^{2}, p_{\tau}^{3}, p_{\tau}^{4}\right)\right\}_{\tau=t-1}^{t+1}$ consistent with the observed average price sequence that contains no price change at $t+1$. As before, I set $p_{t-1}^{i}=\bar{p}_{t-1}$ and $p_{t+1}^{i}=\bar{p}_{t+1}$. I then assume a unique price change was detected at the $d_{t}-t h$ visit of the price collector at $t$ so that $p_{t}^{i<d_{t}}=\bar{p}_{t-1}$ and $p_{t}^{i \geq d_{t}}=\bar{p}_{t+1}$. The point-in-time sequence $\left\{p_{\tau}^{4}\right\}_{\tau=t-1}^{t+1}$ contains no change at $t+1$, and all its elements are strictly positive. Moreover, aside from possible rounding issues, there is at most one sequence $\left\{\left(p_{\tau}^{1}, p_{\tau}^{2}, p_{\tau}^{3}, p_{\tau}^{4}\right)\right\}_{\tau=t-1}^{t+1}$

\footnotetext{
${ }^{41}$ If several price changes occur within a month, then the magnitude of price changes can be either underor overestimated.
} 
consistent with $\left\{\bar{p}_{\tau}\right\}_{\tau=t-1}^{t+1}$ that features no price change within periods $t-1$ and $t+1$ and contains a single change at $t .^{42}$

\section{A.2.2 Multiple price changes}

Suppose now there are $N>2$ consecutive changes to the average-price series starting at $t$. If the price of the item is collected twice per month and the following condition holds

$$
\sum_{n=0}^{N-2}(-1)^{n} \bar{p}_{t+n}=\left(\bar{p}_{t-1}+(-1)^{N} \bar{p}_{t+N-1}\right) / 2,
$$

then I can construct a unique bimonthly series $\left\{\left(p_{\tau}^{1}, p_{\tau}^{2}\right)\right\}_{\tau=t-1}^{t+N}$ that is (a) consistent with the observed monthly averages $\left\{\bar{p}_{\tau}\right\}_{\tau=t-1}^{N-1}$, (b) features no price change within periods $t-1$ and $t+N-1$, (c) has at most one price change per period detected at price collector's second visit and such that (d) the point-in-time sequence $\left\{p_{\tau}^{2}\right\}_{\tau=t-1}^{t+N-1}$ features no price change at $t+N-1$. This series is constructed by setting $p_{t-1}^{i}=\bar{p}_{t-1}, p_{N-1}^{i}=\bar{p}_{N-1}$, and then constructing recursively

$$
\begin{aligned}
p_{t+n}^{1} & =p_{t+n-1}^{2} \\
p_{t+n}^{2} & =2 \bar{p}_{t+n}-p_{t+n-1}^{2}
\end{aligned}
$$

for $n=0, \ldots, N-2$.

Similarly, consider the case of an item whose price is collected four times per month. If there exists $\left(d_{t}, \ldots, d_{t+n}, \ldots d_{t+N-2}\right)$, with $d_{n} \in\{2,3,4\}$, such that the following relation holds:

$$
\begin{aligned}
& \sum_{n=1}^{N-1}(-1)^{n+1}\left(\prod_{j=1}^{n-1}\left(5-d_{t+j}\right)\right)\left(\prod_{j=n+1}^{N-1}\left(d_{t+j}-1\right)\right) \bar{p}_{t+n-1} \\
= & \left(\prod_{n=1}^{N-1}\left(d_{t+n}-1\right)\right) \frac{\bar{p}_{t-1}}{4}+(-1)^{N}\left(\prod_{n=1}^{N-1}\left(5-d_{t+n}\right)\right) \frac{\bar{p}_{t+N-1}}{4}
\end{aligned}
$$

then I can construct a sequence of prices collected $\left\{\left(p_{\tau}^{1}, p_{\tau}^{2}, p_{\tau}^{3}, p_{\tau}^{4}\right)\right\}_{\tau=t-1}^{t+N-1}$ that is (a) consistent with the observed monthly averages $\left\{\bar{p}_{\tau}\right\}_{\tau=t-1}^{N}$, (b) features no price change within periods $t-1$ and $t+N-1$, (c) contains a unique price change detected at $\left(d_{t}, \ldots, d_{n}, \ldots d_{t+N-2}\right)$ and such that (d) there is no change at $t+N-2$ in the monthly point-in-time series $\left\{p_{\tau}^{4}\right\}_{\tau=t-1}^{t+N-1}$.

\footnotetext{
${ }^{42}$ Rounding occurs because the price of items sold for a specific volume or weight generally are converted into a standard unit before appearing in the Diario. For example, the price of a $300 \mathrm{ml}$ bottle of juice would be multiplied by $10 / 3$ to be expressed in pesos per liter.
} 
I proceed by setting $p_{t-1}^{i}=\bar{p}_{t-1}, p_{t+N-1}^{i}=\bar{p}_{t+N-1}$ and then recursively computing

$$
p_{t+n}^{i}=\left\{\begin{array}{cc}
p_{t+n-1}^{4} & \text { if } i<d_{t+n} \\
\left(4 \bar{p}_{t+n}-\left(d_{t+n}-1\right) p_{t+n-1}^{4}\right) /\left(5-d_{t+n}\right) & \text { otherwise }
\end{array} .\right.
$$

Notice that if (1) or (2) is satisfied for some $d_{t+n}=1$, there is no need to adjust the average price at $t+n$. Unlike the case of two consecutive price changes, there is no guarantee that $\left\{\left(p_{\tau}^{1}, p_{\tau}^{2}\right)\right\}_{\tau=t-1}^{t+N}$ and $\left\{\left(p_{\tau}^{1}, p_{\tau}^{2}, p_{\tau}^{3}, p_{\tau}^{4}\right)\right\}_{\tau=t-1}^{t+N-1}$ have strictly positive entries. In the case of food items, there also might be more than one sequence of detection times $\left(d_{t}, \ldots, d_{t+n}, \ldots d_{t+N-2}\right)$ such that condition (2) is satisfied. Thus, in the implementation of the filter, one should make a correction only if it is plausible.

\section{A.2.3 Implementation of the filter}

The filter is applied on an average-price series to extract a point-in-time series of the last price collected over the month. The identifying assumptions are stringent enough to recover the full set of prices collected, $\left\{p_{t}^{i}\right\}$. Those assumptions are:

a) The actual price changes at most once per month;

b) If $\bar{p}_{t}=\bar{p}_{t-1}$, then $p_{t}^{i}=p_{t-1}^{i}=\bar{p}_{t}$;

c) For the first month $t_{0}$ of a price trajectory, $p_{t_{0}}^{i}=\bar{p}_{t_{0}}$;

d) Starting with $N=2$, I identify all sequences of $N$ consecutive changes to the averageprice series. Starting with the oldest sequence of such consecutive price changes,

\section{Bimonthly observations}

if (1) holds and no elements in $\left\{p_{t+n}^{i}\right\}_{n=-1}^{N-1}$ previously have been set to a particular value, then I construct a candidate sequence of collected prices $\left\{\tilde{p}_{t+n}^{i}\right\}_{n=-1}^{N-1}$ as described above. If all elements of $\left\{\tilde{p}_{t+n}^{i}\right\}_{n=-1}^{N-1}$ are strictly positive, and the absolute price changes are smaller than $\ln (5)$, I set $\left\{p_{t+n}^{i}\right\}_{n=-1}^{N-1}=\left\{\tilde{p}_{t+n}^{i}\right\}_{n=-1}^{N-1}$. I then repeat the procedure with the next sequence of $N$ consecutive price changes.

\section{Food items}

for all possible detection times $\left(d_{t}, \ldots, d_{n}, \ldots d_{N-2}\right), i_{n} \in\{2,3,4\}$ such that (2) holds, I construct a candidate sequence of collected prices $\left\{p_{t+n}^{i}\right\}_{n=-1}^{N-1}$ as described above. I discard all sequences containing negative prices or price changes greater than $\ln (5)$. If some candidate corrections remain, I randomly select one of them and use it to set $\left\{p_{t+n}^{i}\right\}_{n=-1}^{N-1}$. I repeat the procedure with the next sequence of $N$ consecutive price changes. 
Once all cases with $N=2$ have been considered, I repeat the entire procedure again with $N=3,4, \ldots, \bar{N}$.

e) For all other cases, I set $p_{t}^{i}=\bar{p}_{t}$.

Once I have identified $\left\{p_{t}^{i}\right\}$, I easily can recover the price trajectories for the last price of the month, $\left\{p_{t}^{2}\right\}$ or $\left\{p_{t}^{4}\right\}$.

\section{A.3 Discussion of the Filter}

In practice, I allow the left- and right-hand sides of (1) and (2) to differ by up to 0.005 to account for the rounding of prices. In the case of food items, I find a multiplicity of candidate solutions in $3 \%$ of the cases for which (2) is satisfied when $N=3$. This proportion grows to $10 \%$ when $N=5$. As a robustness check, I apply the filter for food items on the price trajectories of bimonthly items. Any correction made with $i_{t+n}=2$ or $i_{t+n}=4$ for some $n$ indicates the filter spuriously eliminates a price change not induced by averaging. The filter's performance for various $N$ is presented below:

\begin{tabular}{ccccc}
\hline \hline $\mathbf{N}$ & Cases & Exact & Mixed & Spurious \\
\hline 2 & 142,730 & $94.5 \%$ & $1.0 \%$ & $4.5 \%$ \\
3 & 7,138 & $75.8 \%$ & $2.1 \%$ & $22.1 \%$ \\
4 & 1,415 & $32.9 \%$ & $2.9 \%$ & $64.2 \%$ \\
5 & 596 & $12.2 \%$ & $4.0 \%$ & $83.7 \%$ \\
\hline \hline
\end{tabular}

In the case of two consecutive price changes, the filter corrects 142, 730 sequences. Of those sequences, $94.5 \%$ have a corresponding unique solution with $i_{t}=3$. For an additional $1.0 \%$ of cases, a solution with $i_{t}=3$ is mixed with a spurious solution. In less than one sequence out of twenty, the criterion is satisfied but all candidate solutions have either $i_{t+n}=2$ or $i_{t+n}=4$. As $N$ increases, the proportion of spurious corrections grows quickly. The number of cases detected falls even more rapidly, however, which suggests that leaving long sequences of price changes uncorrected should not effect the overall results. For those reasons, I set $\bar{N}=3$ for food items and $\bar{N}=4$ for bimonthly observations, which are not subject to multiplicity issues. Before computing the statistics in this paper, I drop the first four observations of each price trajectory because they cannot be filtered for all values of $N$ considered.

Finally, all the results in this paper regarding the relationship between inflation and price setting stand if I use the published averaged data directly. The main effect of filtering is to 
reduce the occurence of price changes, lowering $f r, f r^{+}$, and $f r^{-}$while increasing the average absolute magnitude of price changes $d p, d p^{+}$and $d p^{-}$.

\section{Appendix B : Store Samples}

Store samples are used to deal with the high turnover rate of individual items in the clothing categories. When the price of one item in the sample is no longer available, it is substituted by a similar item whose price has been tracked simultaneously. The average price of the sample is then rescaled to avoid creating a price change. The Diario does not report such substitutions. If no substitute is available in the store, the CPI agent might use the price of an item with similar characteristics from a different outlet. For 34 product categories, Banxico mainly reports prices pertaining to store samples rather than to individual items. Using the descriptions published in the Diario, I counted the number of items in each sample and discarded those that did not comprise exactly three elements, the most common sample size.

In this paper, I treat those observations are treated like individual items, which might create an upward bias in the frequency of price changes: Only one item price needs to change to induce a change in the average price in the sample. Moreover, the absolute magnitude of changes typically will be smaller than the underlying changes to individual prices. A lower bound on the aggregate frequency of price changes in the CPI was derived by assuming independent price changes within store samples. ${ }^{43}$ Under this assumption, the average biases are 1.2 percentage points for nonregulated products and 1.8 percentage points for nonregulated goods in the sample. All the main patterns found in the data are preserved.

\section{Appendix C : IPN Basket}

This appendix details the construction of products baskets similar to that of the Inflation Persistence Network. The original categories in the IPN basket are listed in Tables 8 and 9 along with corresponding product matches for Mexico. I use the same method as the IPN to construct category weights. I first assign a 2-digit COICOP group and one of the five main components to each product category in the Mexican CPI, and exclude product categories under Health Care, Education, Cars and Electricity. I then compute the total weight of each stratum - a combination of a COICOP group and main component - for the remaining categories. Finally, the item weights in each stratum are set such that relative weights are the same as in the CPI and add up to the stratum share of all consumer expenses

\footnotetext{
${ }^{43}$ If the frequency of price change is $f r_{3}$ for a sample of three items, and individual price changes are independent within the sample, then the frequency of price changes of an individual item is $f r_{1}=1-$ $\left(1-f r_{3}\right)^{1 / 3}$.
} 
considered. The flip side of this procedure is that some product categories are attributed a disproportionate share of the basket weight because other categories selected within their stratum have relatively small expenditure shares. Milk is the clearest example, receiving more than $13 \%$ of the IPN basket weight while accounting for less than $2 \%$ of total CPI expenditures.

There are a few categories in the IPN basket that lack direct matches in the Mexican CPI. Following the IPN procedure, substitutes are randomly chosen within the same stratum. Substitutes are sought before the 2002 basket revision for Hotel Rooms, Dog Food and Videotape Hiring because no category with individual observations was available at this time. Furthermore, Gasoline, Car Maintenance and Household Maintenance in the Mexican CPI are matched with several products in the IPN basket because no finer breakdown is available before 2002 .

In the case of Gasoline, I use city indexes because there is no alternative category with individual prices in the same stratum. Gas stations are required to post prices set by the Mexican government, and changes follow pre-established rules that are updated periodically. The Household Maintenance category from the Mexican CPI mixes both goods and services before 2002; I compute separate price statistics, however, after sorting items based on the descriptions published in the Diario, choosing relative weights to match relative weights after 2002. Similarly, the category Photographic Material mixes goods and services for the entire time period. Separate indexes therefore are computed as above, and weights are set proportionally to each stratum's share of observations in the product category. Finally, Fax Machine is replaced by Phone Line, and Natural Gas is substituted for Heating Oil. ${ }^{44}$ To be consistent, I include the substitutes in the computation of the stratum weights even though they are not among the categories from which the original IPN sample was drawn.

Finally, two categories in the Mexican basket, Household Maintenance and Phone Line, were introduced in March 1995. The frequency statistics for March to June 1995 are imputed because the filter eliminates the first few observations of every trajectory. In the case of Household Maintenance, the frequency of price changes for March to June 1995 are imputed using a linear projection on the frequency of price changes of items subject to the IVA. For Phone Line, I use instead a linear projection on the frequency of price changes for the unfiltered series for April to June 1995, and I set the March value to the April 1995-February 1997 average.

\footnotetext{
${ }^{44}$ A Fax Machine is categorized as a communication service under the COICOP even though it refers to the price of acquiring the good.
} 
Table 1 : Summary statistics

\begin{tabular}{|c|c|c|}
\hline Period & January 1994 - June 2002 & July 2002 - December 2004 \\
\hline \multicolumn{3}{|l|}{ Price quotes } \\
\hline Total & $4,683,075$ & $1,782,380$ \\
\hline Average per month & 45,913 & 59,413 \\
\hline Trajectories & 71,040 & 107,117 \\
\hline Substitutions & 17,820 & 40,226 \\
\hline \multicolumn{3}{|l|}{ Unweighted frequency (\%) } \\
\hline Price changes & 30.4 & 36.6 \\
\hline Price increases & 21.5 & 22.3 \\
\hline Price decreases & 8.9 & 14.3 \\
\hline \multicolumn{3}{|l|}{ Product categories } \\
\hline Before 03-95 revision & 302 & - \\
\hline After 03-95 revision & 313 & - \\
\hline Unaffected by $03-95$ revision & 284 & - \\
\hline After $07-02$ revision & - & 315 \\
\hline
\end{tabular}

Note: The unweighted frequencies are computed by dividing the number of positive or negative price changes by the total number of price quotes for which a price change can be computed.

Table 2 : Linear regressions results

\begin{tabular}{|c|c|c|c|c|c|c|c|c|c|}
\hline \multirow{3}{*}{$\begin{array}{l}\text { Frequency } \\
\text { Observations } \\
\end{array}$} & \multirow{2}{*}{\multicolumn{3}{|c|}{ Price Changes }} & \multirow{2}{*}{\multicolumn{3}{|c|}{ Price Increases }} & \multirow{2}{*}{\multicolumn{3}{|c|}{ Price Decreases }} \\
\hline & & & & & & & & & \\
\hline & Constant & $\pi$ & R-square & Constant & $\pi$ & R-square & Constant & $\pi$ & R-square \\
\hline All & $\begin{array}{l}27.98 \\
(0.41)\end{array}$ & $\begin{array}{c}0.36 \\
(0.02)\end{array}$ & 0.78 & $\begin{array}{l}16.40 \\
(0.31)\end{array}$ & $\begin{array}{c}0.50 \\
(0.01)\end{array}$ & 0.92 & $\begin{array}{l}11.58 \\
(0.25)\end{array}$ & $\begin{array}{c}-0.14 \\
(0.01)\end{array}$ & 0.58 \\
\hline$\pi<=12.5 \%$ & $\begin{array}{l}30.24 \\
(0.52)\end{array}$ & $\begin{array}{c}-0.02 \\
(0.07)\end{array}$ & 0.00 & $\begin{array}{l}17.41 \\
(0.41)\end{array}$ & $\begin{array}{c}0.31 \\
(0.05)\end{array}$ & 0.36 & $\begin{array}{l}13.06 \\
(0.33)\end{array}$ & $\begin{array}{l}-0.33 \\
(0.04)\end{array}$ & 0.50 \\
\hline$\pi>12.5 \%$ & $\begin{array}{l}26.33 \\
(0.81)\end{array}$ & $\begin{array}{c}0.42 \\
(0.02)\end{array}$ & 0.89 & $\begin{array}{l}17.41 \\
(0.67)\end{array}$ & $\begin{array}{c}0.48 \\
(0.02)\end{array}$ & 0.94 & $\begin{array}{l}8.92 \\
(0.3)\end{array}$ & $\begin{array}{l}-0.06 \\
(0.01)\end{array}$ & 0.57 \\
\hline \multicolumn{10}{|c|}{ Average Magnitude } \\
\hline & \multicolumn{3}{|c|}{ Price Changes } & \multicolumn{3}{|c|}{ Price Increases } & \multicolumn{3}{|c|}{ Price Decreases } \\
\hline Observations & Constant & $\pi$ & R-square & Constant & $\pi$ & R-square & Constant & $\pi$ & R-square \\
\hline All & $\begin{array}{l}0.86 \\
(0.1)\end{array}$ & $\begin{array}{c}1.98 \\
(0.06)\end{array}$ & 0.93 & $\begin{array}{c}8.27 \\
(0.13)\end{array}$ & $\begin{array}{c}0.58 \\
(0.07)\end{array}$ & 0.92 & $\begin{array}{l}10.47 \\
(0.23)\end{array}$ & $\begin{array}{l}-0.50 \\
(0.13)\end{array}$ & 0.13 \\
\hline$\pi<=12.5 \%$ & $\begin{array}{c}0.09 \\
(0.03)\end{array}$ & $\begin{array}{c}3.17 \\
(0.05)\end{array}$ & 0.98 & $\begin{array}{l}7.44 \\
(0.2)\end{array}$ & $\begin{array}{c}-0.39 \\
(0.31)\end{array}$ & 0.03 & $\begin{array}{l}11.45 \\
(0.31)\end{array}$ & $\begin{array}{l}-2.53 \\
(0.49)\end{array}$ & 0.31 \\
\hline$\pi>12.5 \%$ & $\begin{array}{l}2.33 \\
(0.2)\end{array}$ & $\begin{array}{c}1.49 \\
(0.07)\end{array}$ & 0.92 & $\begin{array}{c}7.44 \\
(0.18)\end{array}$ & $\begin{array}{c}0.87 \\
(0.07)\end{array}$ & 0.84 & $\begin{array}{c}9.84 \\
(0.51)\end{array}$ & $\begin{array}{c}-0.23 \\
(0.19)\end{array}$ & 0.04 \\
\hline
\end{tabular}

Note: The numbers in parentheses are standard errors. 
Table 3 : Inflation variance decomposition

\begin{tabular}{|c|c|c|c|c|c|c|}
\hline & \multicolumn{2}{|c|}{ Inflation } & \multicolumn{3}{|c|}{ 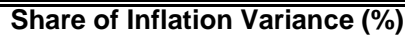 } & \multirow[b]{2}{*}{ Other } \\
\hline & Average & Std Dev & TDP & SDP1 & SDP2 & \\
\hline \multicolumn{7}{|c|}{ Full Sample Period (January 1994 - June 2002) } \\
\hline Full CPI & 14.5 & 13.3 & 42.5 & 4.2 & 21.1 & 32.1 \\
\hline Nonregulated goods & 14.4 & 15.4 & 46.6 & 2.6 & 16.6 & 34.2 \\
\hline Unprocessed food & 12.9 & 20.0 & 89.6 & 0.4 & 2.5 & 7.5 \\
\hline Processed food & 15.0 & 17.8 & 38.1 & 3.4 & 17.5 & 41.0 \\
\hline Nonenergy ind. goods & 14.9 & 15.5 & 26.7 & 8.4 & 23.9 & 41.0 \\
\hline Nonregulated services & 14.6 & 10.6 & 14.6 & 35.2 & 27.3 & 22.9 \\
\hline \multicolumn{7}{|c|}{ Precrisis (January 1994 - December 1994) } \\
\hline Full CPI & 7.7 & 3.2 & 60.6 & 5.0 & 31.0 & 3.4 \\
\hline Nonregulated goods & 7.2 & 2.9 & 60.7 & 3.9 & 27.6 & 7.8 \\
\hline Unprocessed food & 10.4 & 6.5 & 94.6 & 0.4 & 8.9 & -3.8 \\
\hline Processed food & 5.5 & 3.1 & 72.0 & 3.9 & 24.9 & -0.8 \\
\hline Nonenergy ind. goods & 6.7 & 3.4 & 39.7 & 8.1 & 29.7 & 22.5 \\
\hline Nonregulated services & 8.9 & 8.0 & 18.8 & 24.9 & 21.5 & 34.8 \\
\hline \multicolumn{7}{|c|}{ Crisis (January 1995 - June 1999) } \\
\hline Full CPI & 21.5 & 14.1 & 35.6 & 8.9 & 30.1 & 25.4 \\
\hline Nonregulated goods & 22.5 & 16.4 & 39.9 & 6.2 & 27.0 & 26.9 \\
\hline Unprocessed food & 20.0 & 20.1 & 91.6 & 0.9 & 7.7 & -0.3 \\
\hline Processed food & 23.7 & 19.9 & 32.0 & 9.2 & 30.0 & 28.7 \\
\hline Nonenergy ind. goods & 23.2 & 16.4 & 17.4 & 16.7 & 26.5 & 39.3 \\
\hline Nonregulated services & 18.5 & 10.9 & 15.7 & 41.1 & 28.3 & 14.9 \\
\hline \multicolumn{7}{|c|}{ Postcrisis (July 1999 - June 2002) } \\
\hline Full CPI & 5.5 & 4.6 & 83.5 & 0.9 & 5.2 & 10.4 \\
\hline Nonregulated goods & 3.8 & 4.9 & 95.1 & 0.2 & -2.6 & 7.2 \\
\hline Unprocessed food & 2.9 & 17.6 & 93.1 & 0.0 & 0.0 & 6.9 \\
\hline Processed food & 4.0 & 3.6 & 97.9 & 1.4 & -0.9 & 1.5 \\
\hline Nonenergy ind. goods & 4.3 & 3.8 & 86.3 & 1.1 & 10.0 & 2.7 \\
\hline Nonregulated services & 10.0 & 8.2 & 11.4 & 31.7 & 17.9 & 39.0 \\
\hline
\end{tabular}

Notes: The full CPI includes all nonregulated goods and services less housing rents and product categories for which Banxico publishes only indexes. Series were linearly detrended. 
Table 4 : Comparison between Mexico, the United States and Euro area

\begin{tabular}{|c|c|c|c|c|c|}
\hline \multirow[b]{2}{*}{ Period } & \multicolumn{3}{|c|}{ Mexico } & \multirow{2}{*}{$\begin{array}{c}\text { United States } \\
\text { Jan } 1995 \text { - Dec } 1997\end{array}$} & \multirow{2}{*}{$\begin{array}{c}\text { Euro area } \\
\text { Jan } 1996-\text { Dec } 2000\end{array}$} \\
\hline & Mar 1995 - Feb 1997 & Jul 2000 - Jun 2002 & Jan 2003 - Dec 2004 & & \\
\hline Average inflation & 28.5 & 5.4 & 4.3 & 2.3 & 1.6 \\
\hline \multicolumn{6}{|l|}{ Aggregate frequency } \\
\hline BK sample & 32.3 & 23.8 & 20.8 & 26.1 & 15.3 \\
\hline IPN sample & 33.3 & 24.7 & 22.4 & 24.8 & 15.1 \\
\hline \multicolumn{6}{|l|}{ Duration } \\
\hline \multicolumn{6}{|l|}{ Mean duration } \\
\hline BK sample & 3.7 & {$[8.0, ?)$} & {$[9.6, ?)$} & 6.7 & n.a \\
\hline IPN sample & 3.5 & 6.3 & 10.1 & n.a & 13.0 \\
\hline \multicolumn{6}{|l|}{ Median duration } \\
\hline BK sample & 3.0 & 6.1 & 7.1 & 4.6 & n.a. \\
\hline IPN sample & 2.5 & 5.9 & 5.3 & n.a. & 10.6 \\
\hline
\end{tabular}

Note: Figures for the United States and Euro area come from Dhyne et al (2005).

Table 5 : Sample weights of major groups of products (\%)

\begin{tabular}{|c|c|c|c|}
\hline \multirow[b]{2}{*}{ Base year } & \multicolumn{2}{|c|}{ Mexico } & \multirow{2}{*}{$\begin{array}{c}\text { United States } \\
1995 \\
\end{array}$} \\
\hline & 1993 & 2000 & \\
\hline \multicolumn{4}{|l|}{ BK Sample } \\
\hline $\begin{array}{l}\text { Share of total } \\
\text { consumption expenditures }\end{array}$ & 71.1 & 77.9 & 68.9 \\
\hline Nondurable goods & 66.1 & 57.2 & 44.1 \\
\hline Durable goods & 9.0 & 9.8 & 14.7 \\
\hline Services & 24.8 & 33.0 & 41.2 \\
\hline Food & 45.4 & 36.8 & 22.6 \\
\hline Home furnishing & 12.0 & 19.6 & 24.9 \\
\hline Apparel & 9.4 & 7.2 & 8.5 \\
\hline Transportation & 12.8 & 11.5 & 23.1 \\
\hline Medical care & 4.4 & 5.1 & 7.5 \\
\hline Entertainment & 3.8 & 4.9 & 6.2 \\
\hline Other & 12.2 & 14.8 & 7.2 \\
\hline IPN Sample & \multicolumn{2}{|c|}{ Mexico } & Euro area \\
\hline Unprocessed food & 16.6 & 10.7 & 9.3 \\
\hline Processed food & 23.3 & 21.1 & 14.3 \\
\hline Nonenergy industrial goods & 25.2 & 26.1 & 34.4 \\
\hline Energy & 4.7 & 7.8 & 5.8 \\
\hline Services & 30.3 & 34.3 & 36.2 \\
\hline
\end{tabular}

Note: Weights with base year 1993 and 2000 were introduced by Banxico during the March 1995 and July 2002 revisions of the CPI basket. 
Table 6 : Comparison of the frequency of price changes

between Mexico, the United States and Euro area for some special groups

\begin{tabular}{|c|c|c|c|c|}
\hline \multirow{2}{*}{$\begin{array}{l}\text { BK Sample } \\
\text { Period } \\
\end{array}$} & \multicolumn{3}{|c|}{ Mexico } & \multirow{2}{*}{$\begin{array}{c}\text { United States } \\
\text { Jan } 1995 \text { - Dec } 1997\end{array}$} \\
\hline & Mar 1995 - Feb 1997 & Jul 2000 - Jun 2002 & Jan 2003 - Dec 2004 & \\
\hline Average inflation & 28.5 & 5.4 & 4.3 & 2.3 \\
\hline Nondurable goods & 36.6 & 30.2 & 28.7 & 29.9 \\
\hline Durable goods & 37.9 & 18.6 & 17.8 & 30.3 \\
\hline Services & 18.9 & 9.8 & 10.4 & 20.6 \\
\hline \multicolumn{5}{|l|}{ Major groups } \\
\hline Food & 40.5 & 36.3 & 34.3 & 25.3 \\
\hline Home furnishing & 30.9 & 15.3 & 17.7 & 26.4 \\
\hline Apparel & 27.2 & 14.2 & 9.1 & 29.2 \\
\hline Transportation & 30.8 & 13.0 & 12.5 & 39.5 \\
\hline Medical care & 17.4 & 10.6 & 11.4 & 9.3 \\
\hline Entertainment & 11.5 & 7.1 & 10.9 & 11.3 \\
\hline Other & 20.5 & 14.3 & 15.4 & 11.0 \\
\hline \multicolumn{5}{|l|}{ Aggregate frequency } \\
\hline United States weights & 28.7 & 18.5 & 18.5 & 26.1 \\
\hline Mexico weights & 32.3 & 23.8 & 21.6 & - \\
\hline IPN Sample & & Mexico & & Euro area \\
\hline Period & Mar 1995 - Feb 1997 & Jul 2000 - Jun 2002 & Jan 2003 - Dec 2004 & Jan $1996-$ Dec 2000 \\
\hline Average inflation & 28.5 & 5.4 & 4.3 & 1.6 \\
\hline Unprocessed food & 53.4 & 53.1 & 65.4 & 28.3 \\
\hline Processed food & 39.5 & 27.6 & 22.6 & 13.7 \\
\hline Nonenergy industrial goods & 28.9 & 17.7 & 16.6 & 9.2 \\
\hline Energy & 54.3 & 39.8 & 55.9 & 78.0 \\
\hline Services & 16.6 & 9.5 & 5.7 & 5.6 \\
\hline \multicolumn{5}{|l|}{ Aggregate frequency } \\
\hline Euro area weights & 27.6 & 23.5 & 20.3 & 15.1 \\
\hline Mexico weights & 33.3 & 24.7 & 22.4 & - \\
\hline
\end{tabular}

Notes: The U.S. statistics are computed using the figures in Bils and Klenow (2004) and are inclusive of sales. The figures for the Euro area are from Dhyne et al. (2005). 


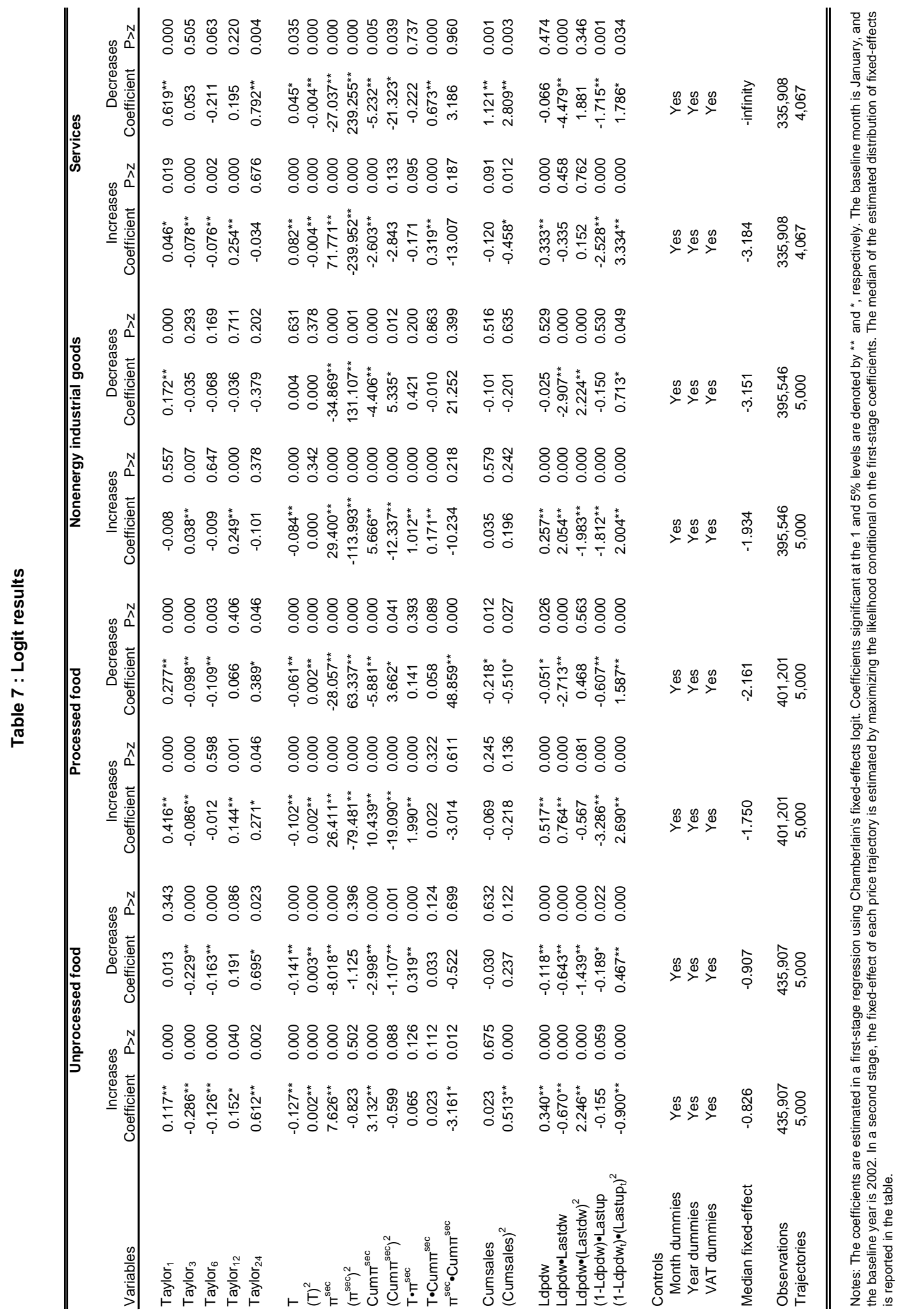




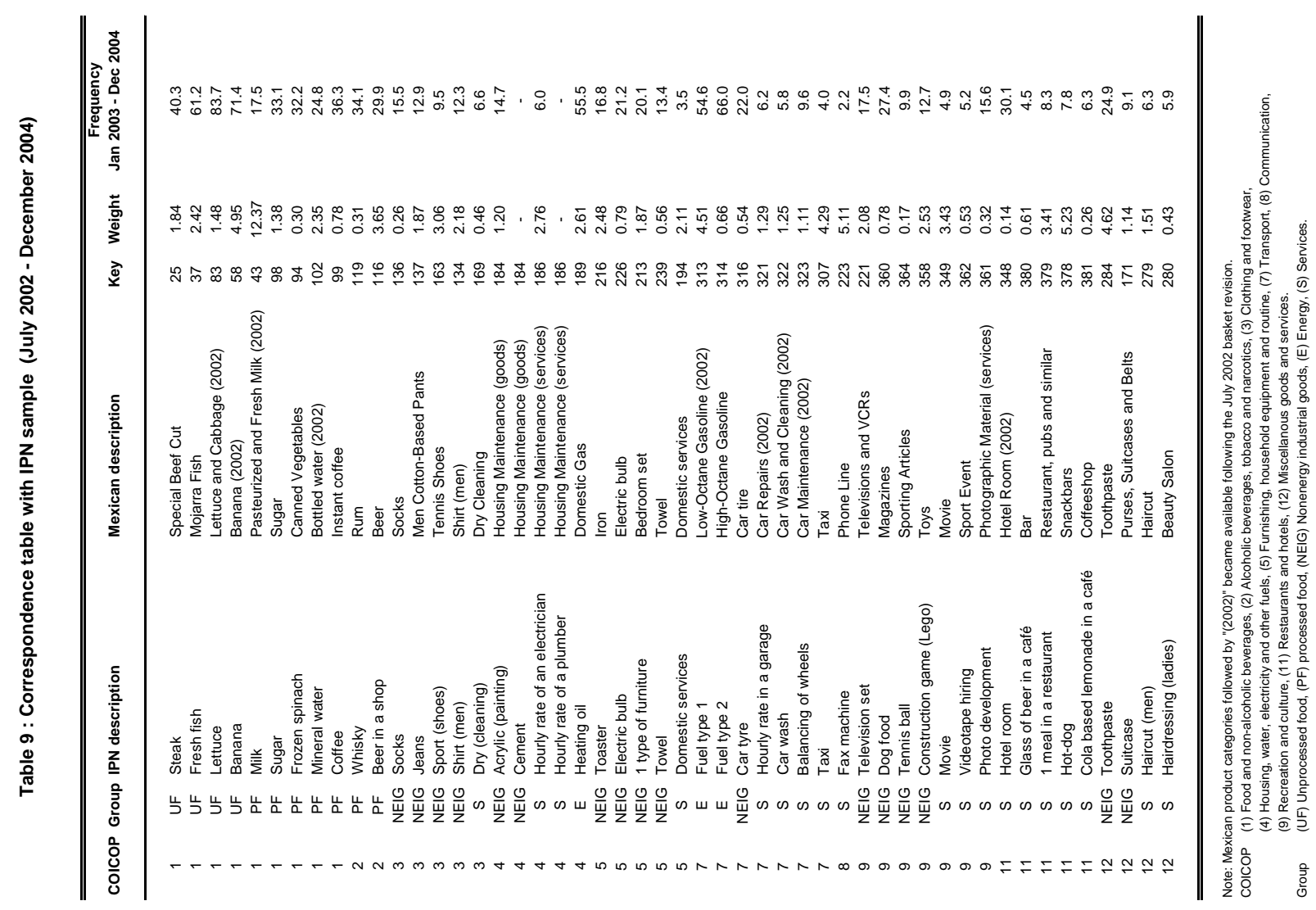




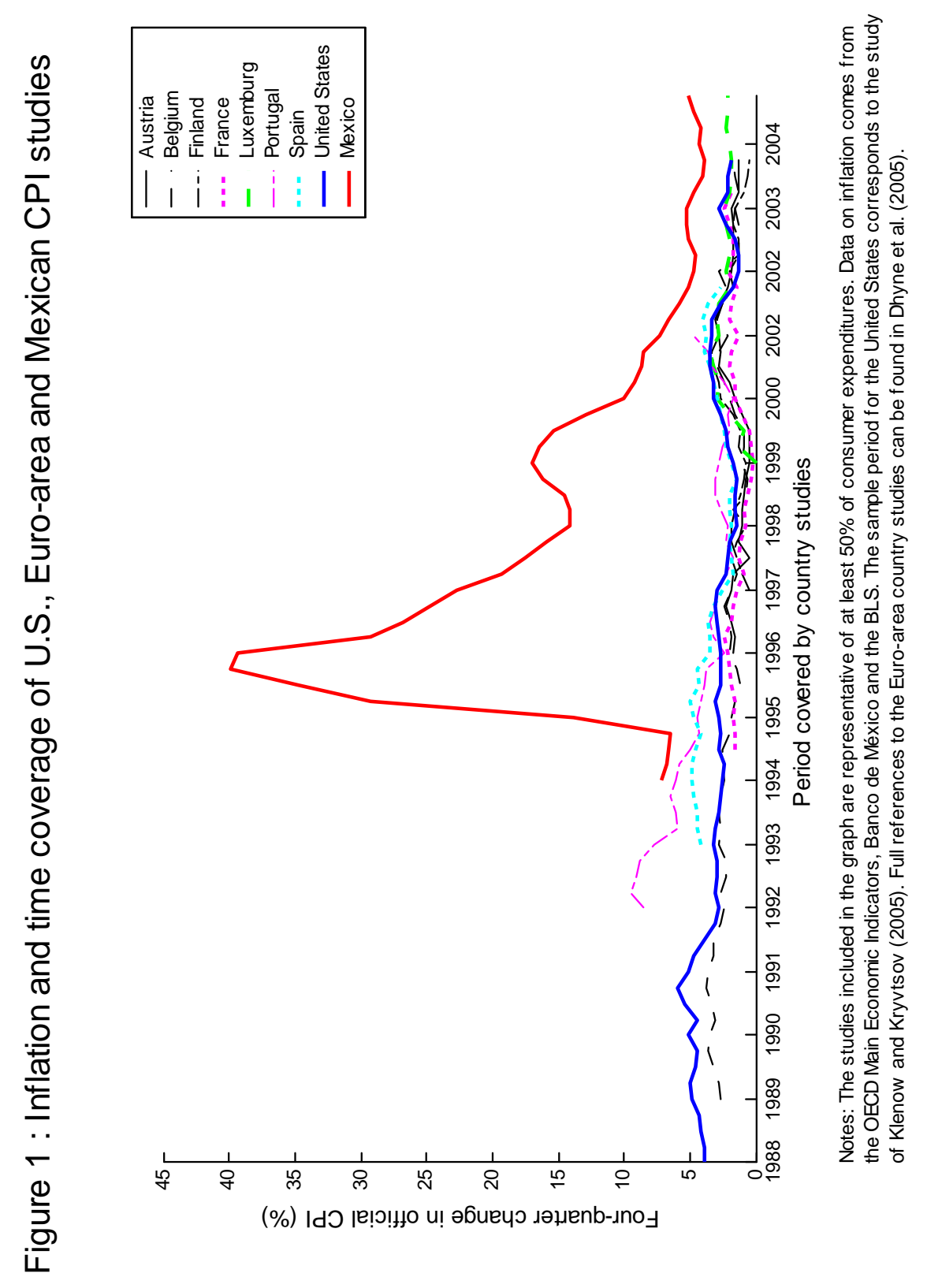



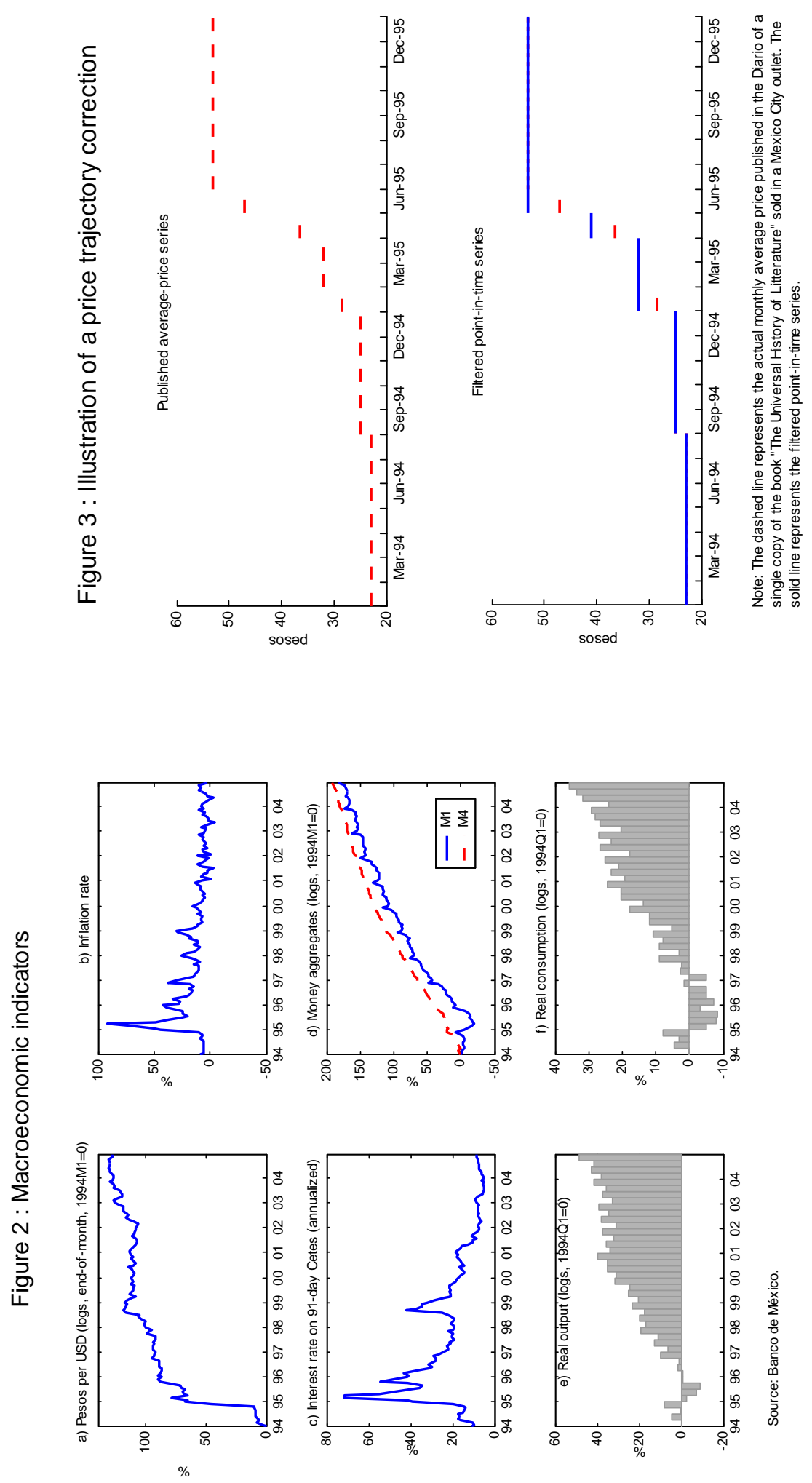
Figure 4 : Aggregate frequency of price changes (nonregulated goods)
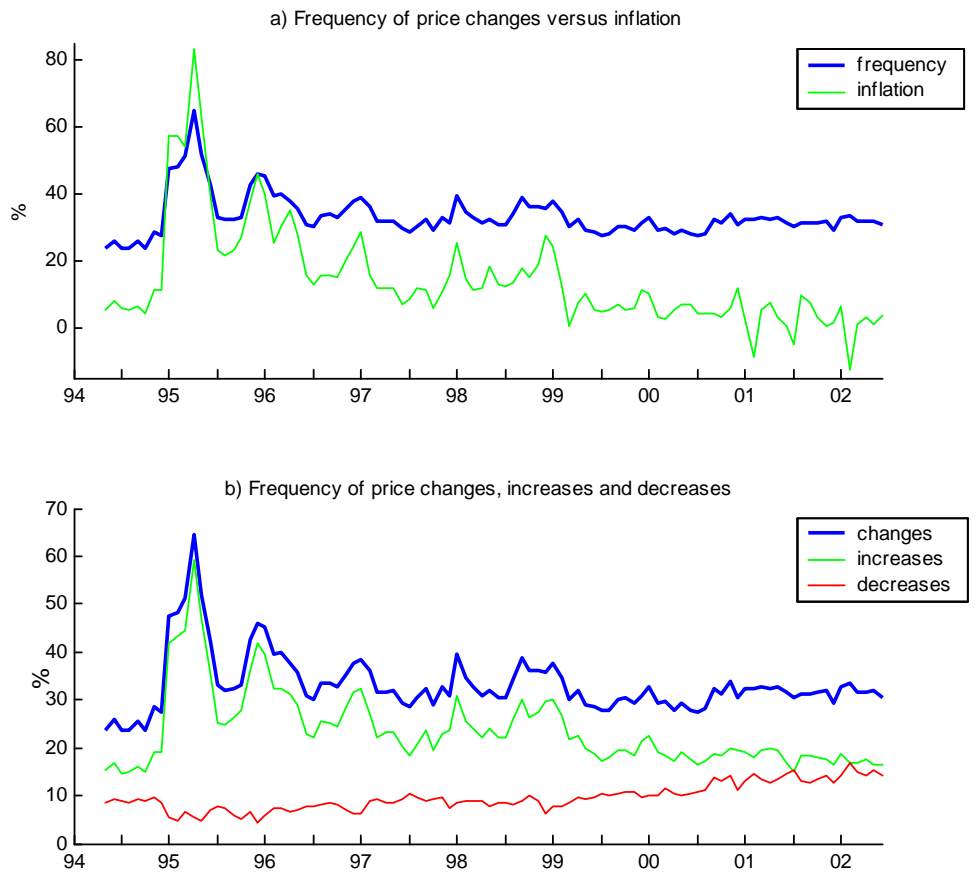

Figure 5 : Scatter plot of the frequency of price changes against inflation (nonregulated goods)
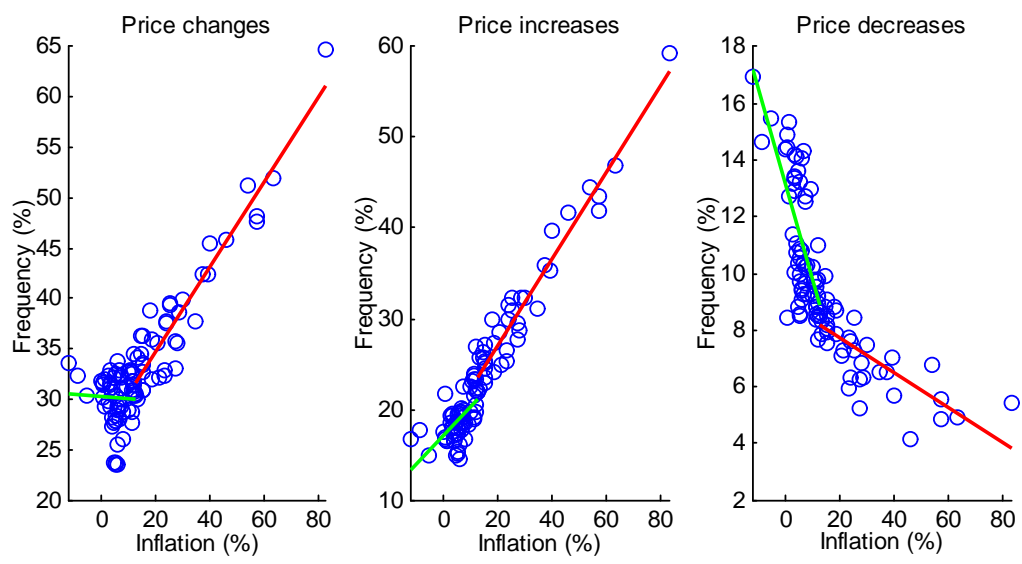

Note: Each graph displays linear regression lines using all observations below and above $12.5 \%$ annual inflation respectively. The regression statistics are presented in Table 2. 
Figure 6 : Average magnitude of price changes (nonregulated goods)
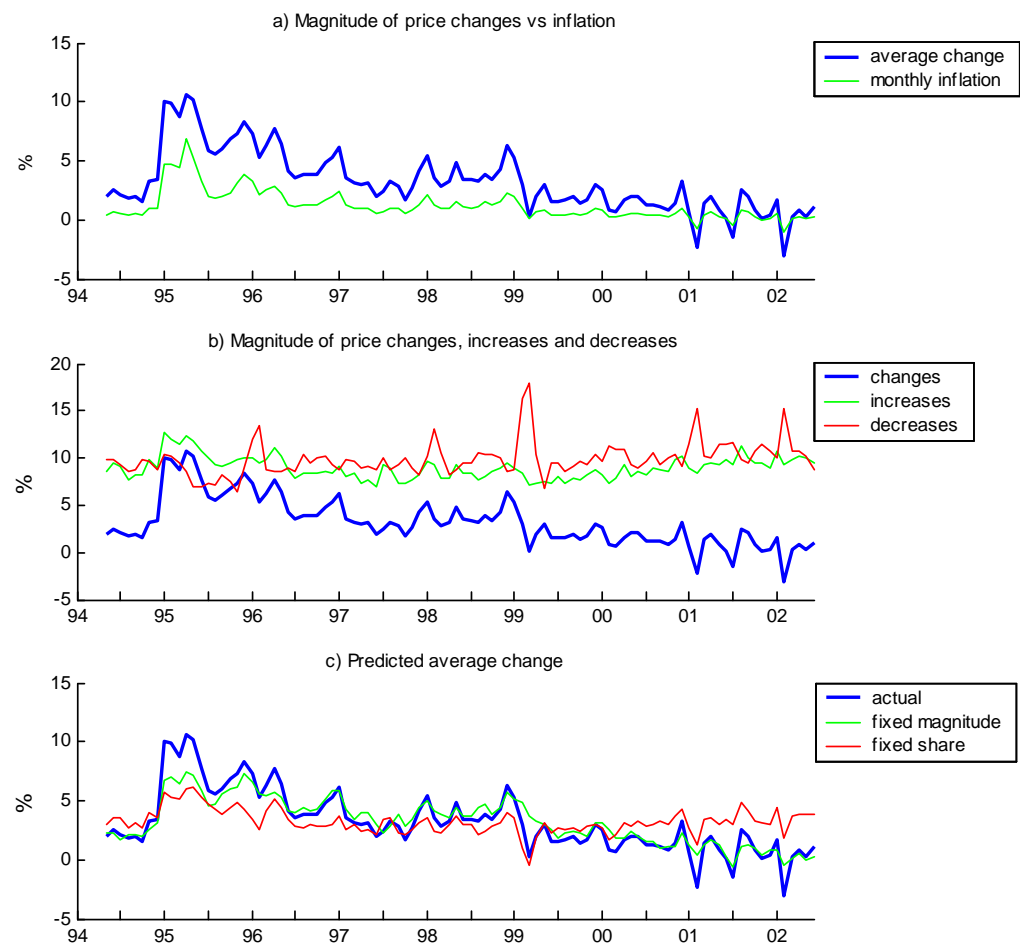

Figure 7 : Scatter plot of the average price change against inflation (nonregulated goods)
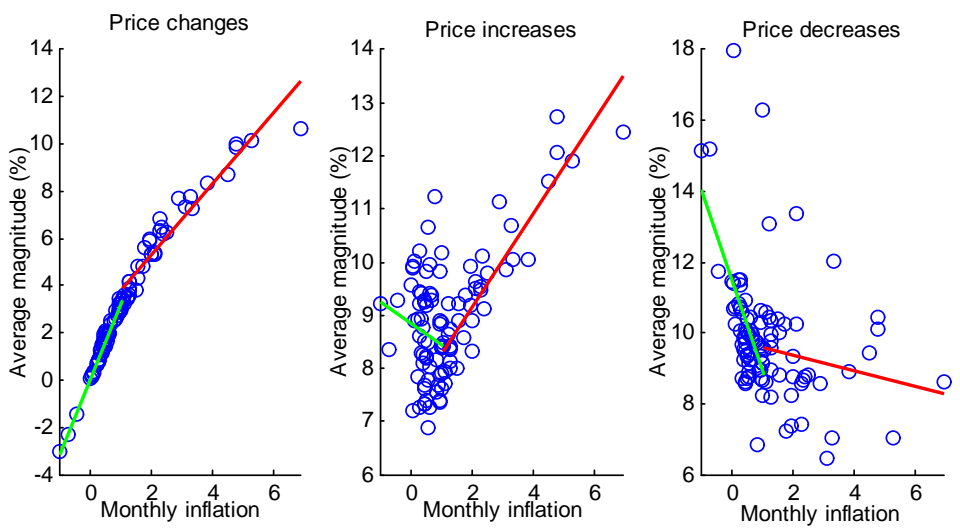

Note: Each graph displays linear regression lines using all observations below and above $12.5 \%$ annual inflation respectively. The regression statistics are presented in Table 2. 
Figure 8: Distribution of non-zero price changes (nonregulated goods)
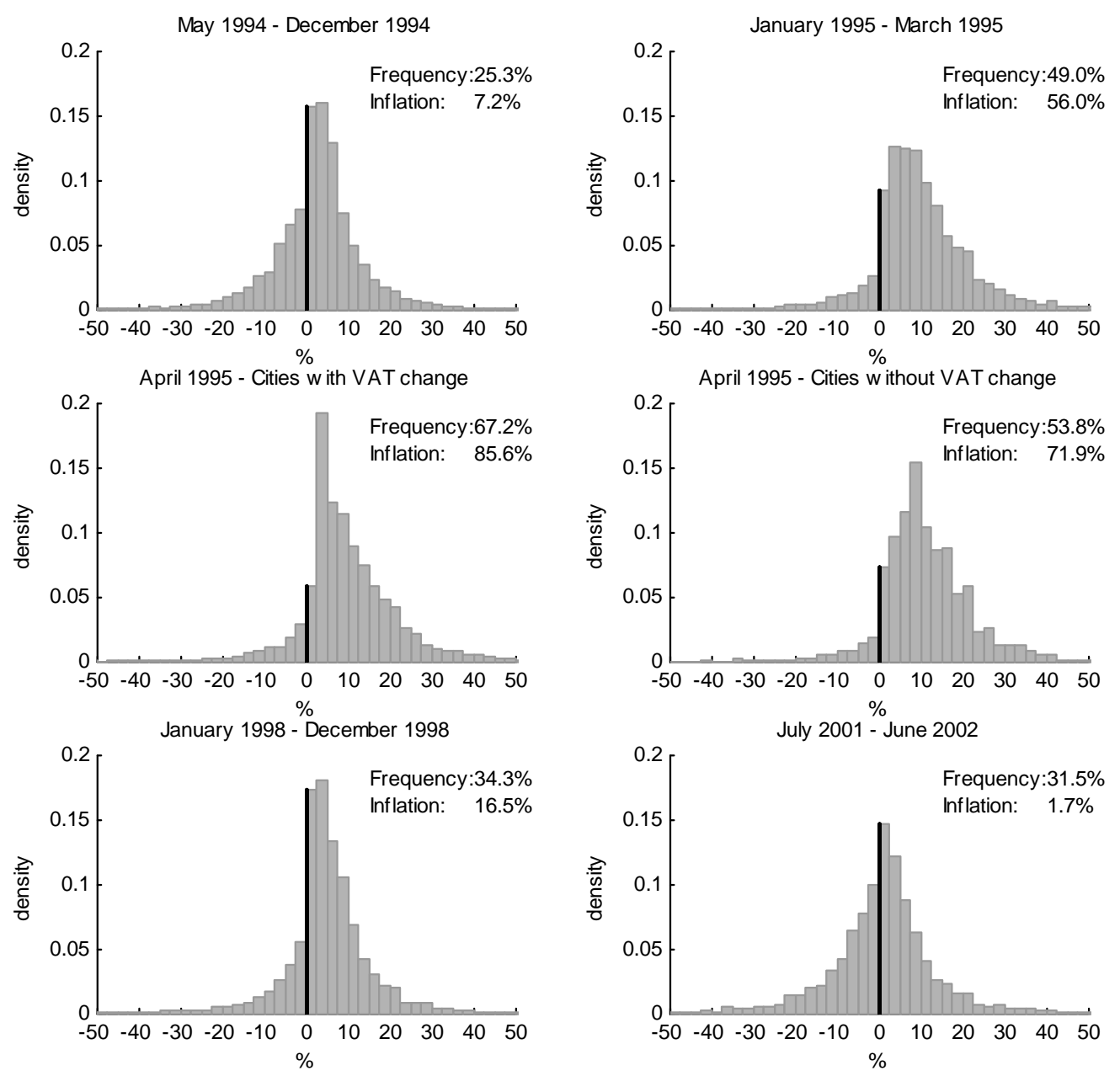
Figure 9 : Frequency of price changes per sector

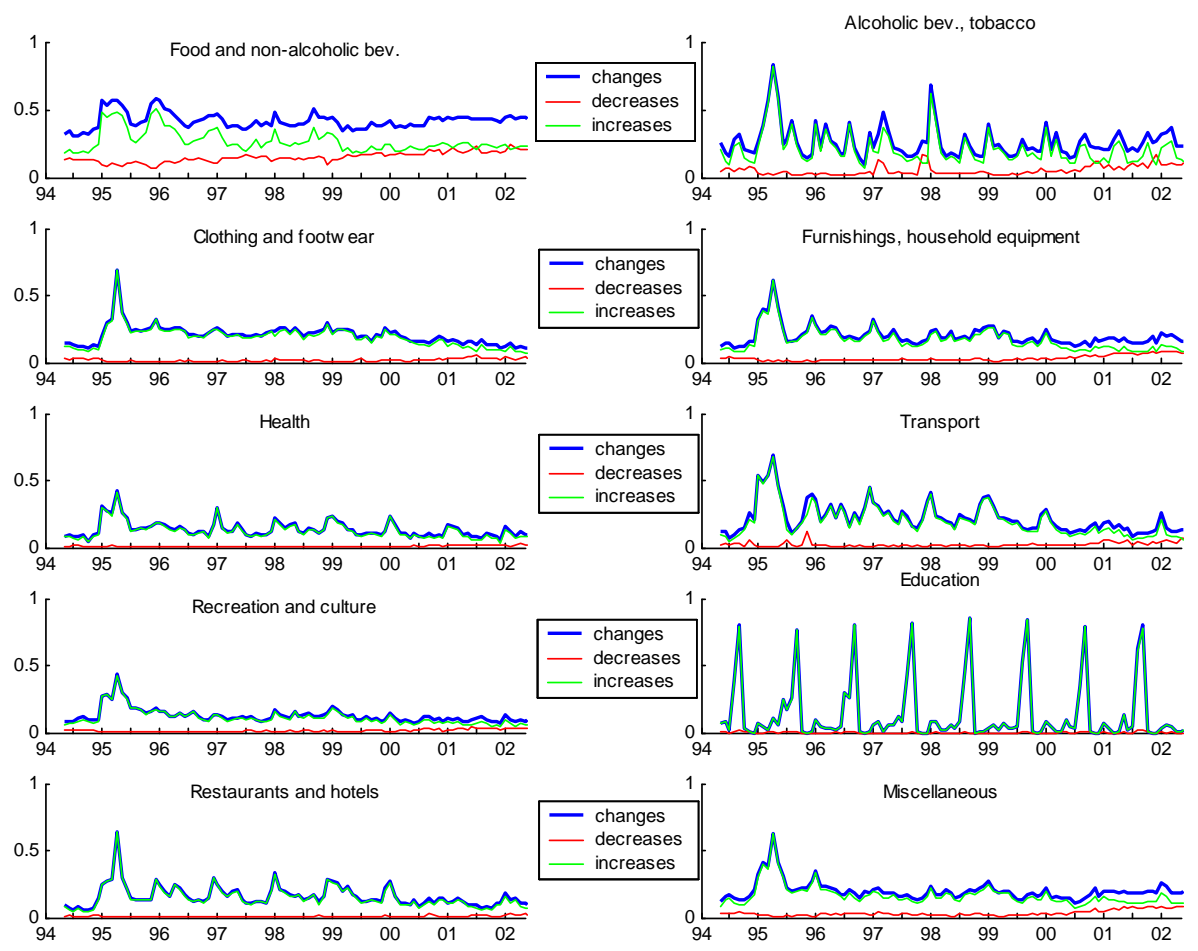

Figure 10 : Effects of April 1, 1995 VAT change
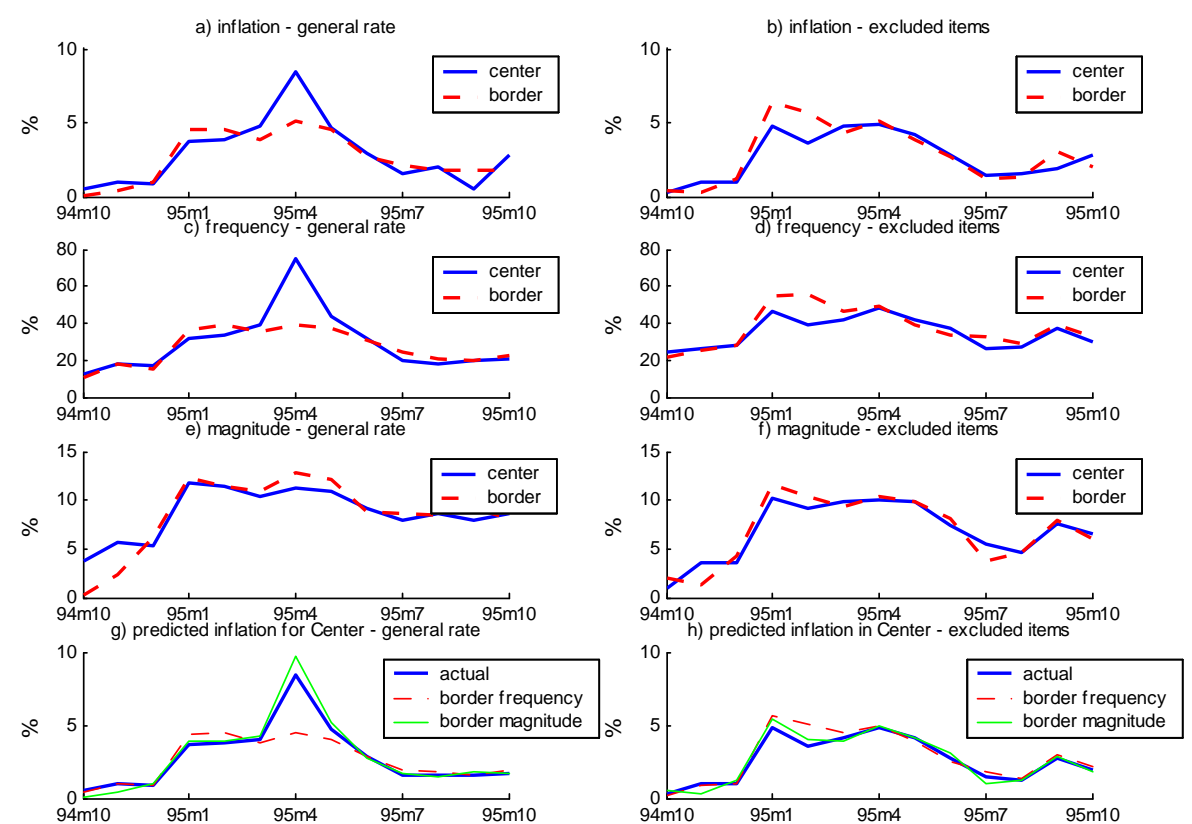

Note: The sample is broken dow $\mathrm{n}$ betw een items that are taxed (general rate) and those that are not (excluded items). It is further divided betw een geographic areas where the general rate changed in April 1995 (center) and those where it remained the same (border). 

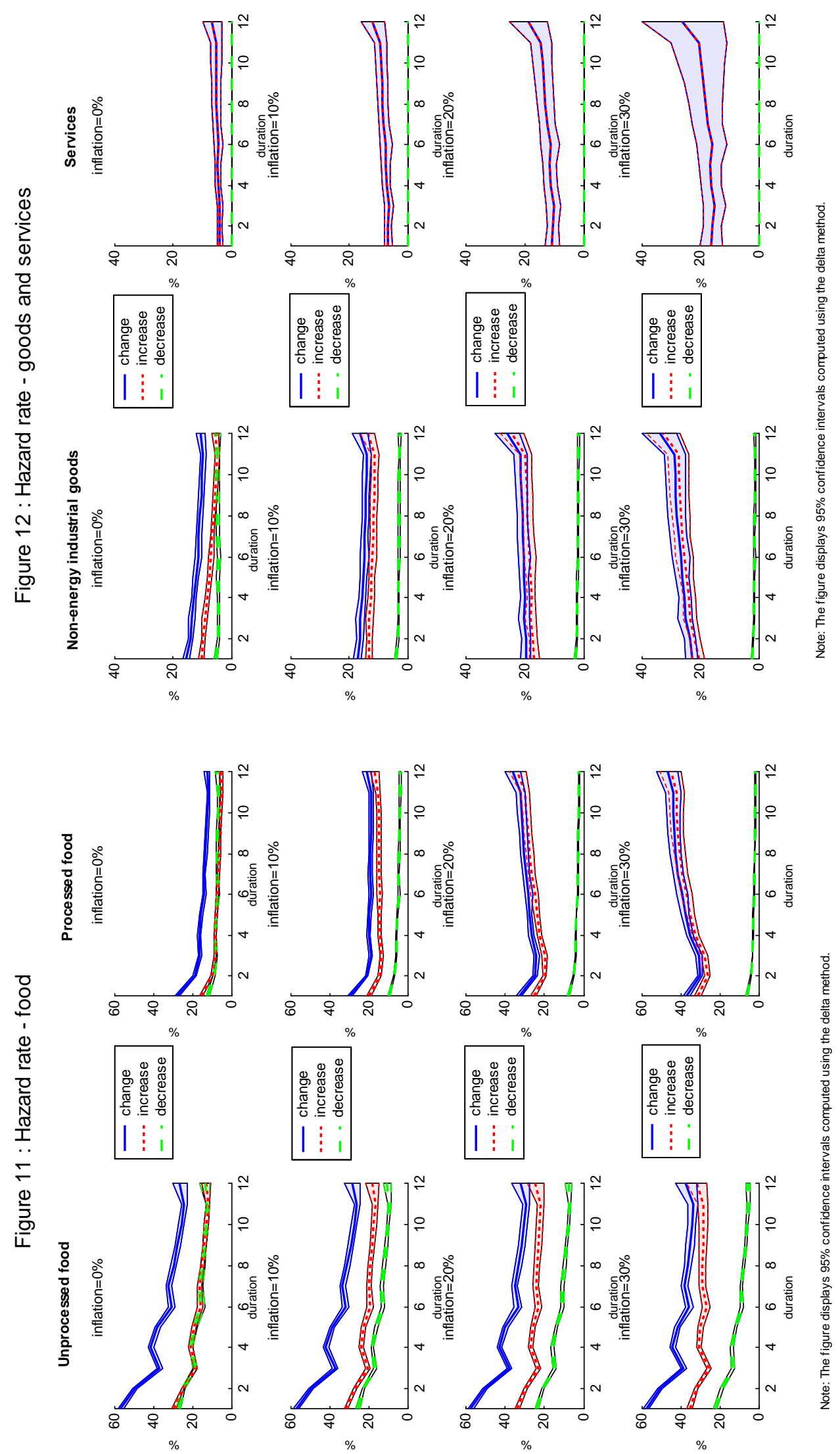